Illinois State University

ISU ReD: Research and eData

Theses and Dissertations

10-17-2017

\title{
Addressing Mental Health, Substance Abuse, and Recidivism in the Juvenile Justice System
}

Danielle N. Gieschen

Illinois State University, dngiesc@ilstu.edu

Follow this and additional works at: https://ir.library.illinoisstate.edu/etd

Part of the Psychology Commons

\section{Recommended Citation}

Gieschen, Danielle N., "Addressing Mental Health, Substance Abuse, and Recidivism in the Juvenile Justice System" (2017). Theses and Dissertations. 856.

https://ir.library.illinoisstate.edu/etd/856

This Thesis is brought to you for free and open access by ISU ReD: Research and eData. It has been accepted for inclusion in Theses and Dissertations by an authorized administrator of ISU ReD: Research and eData. For more information, please contact ISUReD@ilstu.edu. 


\title{
ADDRESSING MENTAL HEALTH, SUBSTANCE ABUSE, AND RECIDIVISM IN THE JUVENILE JUSTICE SYSTEM
}

\author{
Danielle N. Gieschen
}

80 Pages

Research has shown links between mental health concerns, substance abuse concerns, and recidivism for youth. However, the vast majority of studies have not examined the impact that receiving services or treatment compliance has on this relationship. In this study, mental health concerns, mental health treatment, alcohol and substance abuse concerns, alcohol and substance abuse treatment and recidivism within the juvenile justice system were examined. The electronic and paper probation files and the paper court files for 77 youth were examined to determine the impact that receiving mental health or substance abuse services has on reducing the likelihood of recidivism. Furthermore, the impact of treatment compliance with these services was examined. Hierarchical regressions and correlations were conducted to examine the relation between these variables. Results indicated that youth who were receiving treatment for mental health or substance abuse concerns were more likely to reoffend than youth who were not receiving these services. Furthermore, treatment compliance was not significantly correlated with recidivism. Given the limited research in this area, these results should be tested again against different data sets with more diverse youth. Recommendations for changes in public policy have been made based on the results of this study. 
KEYWORDS: mental health; mental health services; substance abuse; alcohol use; substance abuse services; treatment compliance; recidivism; juvenile justice 


\section{ADDRESSING MENTAL HEALTH, SUBSTANCE ABUSE, AND RECIDIVISM}

IN THE JUVENILE JUSTICE SYSTEM

DANIELLE N. GIESCHEN

A Thesis Submitted in Partial Fulfillment of the Requirements for the Degree of

MASTER OF SCIENCE

Department of Psychology

\section{ILLINOIS STATE UNIVERSITY}


(C) 2017 Danielle N. Gieschen 


\section{ADDRESSING MENTAL HEALTH, SUBSTANCE ABUSE, AND RECIDIVISM \\ IN THE JUVENILE JUSTICE SYSTEM}

DANIELLE N. GIESCHEN

COMMITTEE MEMBERS:

Renée M. Tobin, Co-Chair

Adena B. Meyers, Co-Chair 


\section{ACKNOWLEDGMENTS}

I would like to thank Renée Tobin, Adena Meyers, Alycia Hund, and Brenda Huber for their guidance and support on this project. I would also like to thank Judge Bauknecht, Shelby Bivens, and Ron Baker for their assistance gathering data within the Juvenile Justice System.

Additionally, I would like to thank the research assistants who helped me extract and code the data. Last but not least, I would like to thank my cohort members, my parents, and my fiancé for their endless encouragement and support today and always.

D.N.G. 


\section{CONTENTS}

\section{Page}

ACKNOWLEDGMENTS

CONTENTS

TABLES

iv

CHAPTER I: REVIEW OF RELATED LITERATURE

Youth Serviced in the Juvenile Court System

Current Rates of Youth in the Juvenile Court System

Mental Health in the Juvenile Justice System

Common Approaches Addressing Mental Health

Substance and Alcohol Use in the Juvenile Justice System

Common Approaches Addressing Substance Use

Rural Communities

CHAPTER II: THE CURRENT STUDY

Overview

Participants

Materials

Procedure

Probation Logs

Court Records

Results 
Supplemental Analyses

$\begin{array}{ll}\text { CHAPTER V: DISCUSSION } & 36\end{array}$

$\begin{array}{ll}\text { Strengths and Limitations } & 41\end{array}$

$\begin{array}{ll}\text { Future Research } & 43\end{array}$

$\begin{array}{ll}\text { Public Policy Implications } & 45\end{array}$

$\begin{array}{ll}\text { REFERENCES } & 47\end{array}$

APPENDIX A: TRAINING MANUAL

APPENDIX B: TREATMENT COMPLIANCE MATRIX 80 


\section{TABLES}

Table

Page

1. Mental health concerns, treatment, and recidivism $\quad 58$

2. Alcohol/substance abuse concerns, treatment, and recidivism 58

3. Substance abuse concerns, treatment, and recidivism 59

4. Total time in juvenile justice system, mental health concerns, treatment, and 60 recidivism

5. Total time in juvenile justice system, alcohol/substance abuse concerns, treatment, 61 and recidivism 


\section{CHAPTER I: REVIEW OF RELATED LITERATURE}

In 1899, the first juvenile court in the United States was established in Cook County Illinois. This court was established with the understanding that youth did not have fully developed moral and cognitive capacities (Sickmund \& Puzzanchera, 2014). Thirty-two states had established a juvenile court system by 1910, and by 1925, 48 states had established a juvenile court or probation service system. These juvenile courts took a different approach with their offenders than adult criminal courts, conceptualizing youth offenders as having a greater capacity to reintegrate into the general community. It took juvenile courts almost 50 years to become more formalized with a standardized procedure across all states. As a result of these standardized procedures, juvenile courts adhered to similar laws as the criminal justice system that made it easier to transfer juvenile offenders from the juvenile justice system to the criminal justice system, gave criminal and juvenile courts expanded sentencing options, modified or removed traditional juvenile court confidentiality provision making records and proceedings more open, and increased the role of victims of juvenile crime in the juvenile justice process (Ketcham, 1977; Sickmund \& Puzzanchera, 2014).

Since this standardized procedure was put in place, juvenile courts have served youth using related frameworks, provided similar services, and were accountable for the same outcomes. Protecting youth from the consequences of an adult criminal court and separating incarcerated juveniles from the influences of adult criminals were the main reasons for the establishment of juvenile courts (Zang, 2015). Additionally, the juvenile court system aligned itself with the belief that youth in conflict with the law may require a broader range of services than is typically available in criminal or municipal courts. As a result, juvenile courts took on the responsibility of reducing the barriers that exist for youth to be rehabilitated as well as holding 
juvenile offenders accountable for their behavior and providing a greater range of services that youth may require (Bazemore, 1999; Sickmund \& Puzzanchera, 2014; Zang, 2015).

Furthermore, juvenile courts are able to take adverse family experiences, as well as emotional, behavioral, and cognitive functioning into consideration for sentencing guidelines, and intervene in the lives of abused and neglected youth who lack a safe and nurturing environment (Cocozza \& Schufelt, 2006; Cocozza \& Skowyra, 2000; Sickmund \& Puzzanchera, 2014; Zang, 2015). The juvenile justice system could now intervene in the lives of youth in many different areas of their life in order to enhance their ability to live productively and responsibly in the community.

By 1925, juvenile courts spread to 48 states and took a retribution and punishment approach, and a large number of youths were transferred to criminal courts, receiving longer sentences than they currently do, and getting charged younger than they currently do (Cocozza \& Skowyra, 2000). Until relatively recently the courts continued to follow this approach, but in 1999, U.S. Congress mandated that the juvenile justice system provide comprehensive mental health and substance abuse screening and treatment programs for youth (Manisses Communications Group, Inc., 1999). This forced the juvenile justice system to address mental health-related issues and treatment. Currently, there is no standardized system of care that exists regarding how juvenile courts should address mental health concerns, and as a result strategies have been implemented sporadically and without monitoring the effectiveness of the programs (Cocozza \& Skowyra, 2000).

Nonetheless, there are a few comprehensive strategies that are emerging as effective, such as cross-system collaboration or diversion programs. The first strategy calls for crosssystem collaboration, with multiple agencies within the community coordinating their services in order to create one comprehensive treatment plan for the minor (Cocozza \& Skowyra, 2000; 
Kamradt, 1998). Courts taking this approach have begun linking youth with existing communitybased mental health and substance abuse services, and monitoring their compliance with treatment and treatment programming as an aspect of their probation order (Cocozza \& Shufelt, 2006). The second approach calls to divert youth with serious mental health disorders from the juvenile justice system to other programs more suitable for their needs (Cocozza \& Skowyra, 2000). Programs that take this approach provide the court with a plan containing communitybased resources and services that the youth will be referred to based on the results of a comprehensive evaluation of the needs of the youth and their family.

\section{Youth Serviced in the Juvenile Court System}

The juvenile court system has both upper and lower age boundaries that determine which youth can be under the supervision of a juvenile court judge and receive access to these services. The lower age boundary refers to the youngest age at which an individual can be considered a delinquent under juvenile court jurisdiction. Lower age boundaries were identified by only 18 out of 50 states in 2014. The lower age boundaries in these 18 states range from the age of six (i.e., North Carolina) or seven (e.g., Connecticut, Maryland, Massachusetts, New York) to 10 (e.g., Arkansas, Colorado, Louisiana, Minnesota, Mississippi, Pennsylvania, South Dakota, Texas, Vermont, Wisconsin). A lower age boundary is not set for the remaining 32 states (Zang, 2015).

The upper age boundary refers to the oldest age at which an individual can be considered a delinquent and receive services and supervision under juvenile court jurisdiction. In 40 of 50 states and 5 of 5 territories, the upper age boundary is age 17 as of 2014. However, in eight states, the upper age boundary is age 16 (e.g., Georgia, Louisiana, Michigan, Missouri, New Hampshire, South Carolina, Texas, and Wisconsin), with two states (e.g., New York and North 
Carolina) having an upper age boundary of age 15 (Zang, 2015). However, juvenile courts also have the ability to extend the age boundaries and provide supervision for an individual whose contact with the juvenile court occurred before the end of the upper age boundary in that state. Extensions typically occur so a juvenile court judge can monitor the completion of services the youth began receiving under supervision. In 2014, four states (e.g., Nebraska, Oklahoma, Rhode Island, and Texas) and one territory (i.e., The Virgin Islands) have an extended boundary of 18, six states (e.g., Alaska, Connecticut, Iowa, Mississippi, New Jersey, and North Dakota) have an extended boundary of 19, six states (e.g., California, Kansas, Montana, Oregon, Vermont, and Wisconsin) have an extended boundary which ranges from 21 to 24 , and two states (e.g., Colorado and Hawaii) have no specified age limit. The remaining 32 states and four territories have an extended age through 20 (Zang, 2015).

\section{Current Rates of Youth in the Juvenile Court System}

There is an alarming number of youth involved in the juvenile justice system. Recent studies estimate that more than 31 million adolescents are involved in the juvenile court system, with 1,058,500 youth being supervised by the court system in 2013 alone (Hockenberry \& Puzzanchera, 2015; Puzzanchera, Adams, \& Sickmund, 2011). This represents $42 \%$ of youth within the general population, as there are 74 million youth within America as of 2014 (Colby \& Ortman, 2015). A census done by the Office of Juvenile Justice and Delinquency Prevention in 2012 reported that although the juvenile offender population dropped 14\% from 2010 to 2012, $21 \%$ of the facilities reported being overcrowded and relying on makeshift beds for their youth (Hockenberry, Sickmund, \& Sladky, 2015). Furthermore, in 2010, an estimated 46\% of juvenile cases did not end with supervision by the court system, but rather resulted in informal probation, restitution, community service, or a referral to another agency for services (Sickmund \& 
Puzzanchera, 2014). These statistics exemplify the large number of youth that are involved in some way with the juvenile justice system, and result in questions surrounding the types of services that these youth receive to reduce recidivism. Recidivism refers to an individual's relapse back into criminal behavior after they have begun an intervention for a previous crime. Recidivism is measured by criminal acts that result in rearrests or reconvictions during a threeyear period after the initial crime (National Institute of Justice, 2014)

High prevalence rates of mental health disorders have been found among youth involved in the juvenile justice system, ranging between 65\% and 70\% (Cauffman, 2004; Shufelt \& Cocozza, 2006). In contrast, rates of mental health disorders in the general community is estimated at 20\% (Cauffman, 2004; Shufelt \& Cocozza, 2006). Additionally, studies have shown that $25 \%$ of youth within the juvenile justice system experience a combination of severe disorders, such as major depression or generalized anxiety, compared to around $9 \%$ of the youth within the general community, and that more than $60 \%$ of the juvenile offenders meet the criteria for three or more diagnoses (Cocozza \& Shufelt, 2006; Cocozza \& Skowyra, 2000).

Similarly, research has documented high rates of substance use among youth involved in the juvenile justice system. Substance Use Disorders within the juvenile justice population is alarmingly high, with even higher rates of youths reporting substance use but not qualifying for a diagnosis. Adolescents involved in the juvenile justice system have a significantly higher percentage of substance use disorders than youth who have never been involved with the system, with approximately $50 \%$ of juvenile offenders having a substance use disorder compared to the $8 \%$ of youth who have not had contact with the juvenile justice system in 2002 (Schufelt \& Cocozza, 2006; Chassin, 2008). Furthermore, Sickmund and Puzzanchera (2014) reported that youth with substance use disorders were more likely to offend over the 7-year period of their 
study than youth with no substance use issues, and that heavier substance users were more likely to be arrested than youth who used less frequently.

These reports of mental health needs and substance abuse among youth in the juvenile justice system call for further research on the effectiveness of juvenile courts services, and have put pressure on the judicial system, as well as social service providers, to develop a more effective response for youth within the juvenile justice system. Moreover, they highlight the additional supports that this population requires, as well as the challenges that juvenile offenders commonly experience. The purpose of this study is to explore how mental health and alcohol or substance abuse concerns influences recidivism, and how this relationship is influenced by receiving treatment and treatment compliance.

\section{Mental Health in the Juvenile Justice System}

Limited research has begun to surface regarding youth's mental health within the juvenile justice system. Cocozza and Skowyra (2000) note that much of this research is inadequate and methodologically flawed due to inconsistent definitions and assessment of mental illnesses, biased sampling, retrospective case reports, and non-standardized measurement instruments. The authors identified the absence of a shared definition of mental illness within the literature as one of the biggest difficulties in drawing sound conclusions. They analyzed the different terms commonly used in research, and found that the most common terms include "mental health disorder," "mental illness," "serious mental health disorder," and "serious emotional disturbance." They found that the term "mental health disorder" was used to categorize youth with a diagnosable mental health disorder that met the formal diagnostic criteria in the DSM-IV. The researchers further explained that the terms "serious mental health disorder" and "serious emotional disturbance" have been defined in multiple ways, but most commonly were used to 
identify youth experiencing particularly severe disorders, such as schizophrenia, major depression, and bipolar disorder are often highlighted as examples of "serious mental health disorders" or "serious emotional disturbances." The authors do not offer an explanation of the term "mental illness," but suggest that "mental illness" is defined even more inconsistently, and is commonly used to identify anyone who would qualify for a diagnosis or would benefit from mental health services. The following summary of the research literature should be interpreted within the context of the previously mentioned concerns, and with the understanding of the meaning behind the different categorical terms. The current research will use the term "mental illness," focusing specifically upon youth who were identified as benefiting from mental health services.

Shufelt and Cocozza (2006) examined mental health diagnoses within the juvenile justice system more closely and found that youth in contact with the juvenile justice system experience high rates of mental health disorders including disruptive disorders (46.5\%), substance abuse disorders (46.2\%), anxiety disorders (34.4\%), and mood disorders (18.3\%). The high rates of disruptive disorder diagnoses among youth involved in the juvenile justice system seems logical, as characteristics of these disorders are similar to characteristics of delinquent youth in general. It is estimated that almost $80 \%$ of the juvenile justice population meets the diagnostic criteria for Conduct Disorder (Cocozza \& Skowyra, 2000). However, in order to determine if Conduct Disorder and Substance Use Disorder accounted for the overall high prevalence rates of mental health disorders, Shufelt and Cocozza (2006) examined the disorders more closely and found that high rates of youth within the juvenile justice system are still being identified as having a mental health disorder after removing Conduct Disorder (66.3\%), Substance Use Disorder (61.8\%), and combined Conduct Disorder and Substance Use Disorder (45.5\%). Gordon et al. (2012) found 
that youth with ADHD were more likely than youth without ADHD to be rearrested and reconvicted. The prevalence of $\mathrm{ADHD}$ has been found to be higher within detained youth than within the general population, with approximately $20 \%$ of youth within the juvenile justice system having a diagnosis of $\mathrm{ADHD}$, compared to $5 \%$ in the general population (American Psychiatric Association, 2013; Gordon \& Moore, 2005; Vreugdenhil et al., 2004). Vreugdenhil et al. (2004) hypothesized that this higher prevalence was due to the fact that many youth with ADHD exhibit externalizing symptoms, often leading to the development of Conduct Disorder as a comorbid diagnosis.

These results exemplify the high rate of comorbid diagnoses that youth in the juvenile justice system experience, highlighting the severity of their mental health concerns. Research has shown that more than one-half of youth offenders have more than one disorder (Espinosa et al., 2013; Liebenberg \& Ungar, 2014; Teplin et al, 2002; Trupin et al., 2004; Weemhoff \& Villarruel, 2011), with strong links between depression, anxiety and recidivism (Aalsma et al., 2015; Cottle, Lee, \& Heilbrun, 2001; Grisso, 2008; Sedlak \& McPherson, 2010). Cottle et al. (2001) conducted a meta-analysis of 23 studies examining 15,265 anxiety or depression diagnoses among youth involved in the juvenile justice system. They found that a diagnosis of one or more of these internalizing problems was one of the strongest predictors of juvenile recidivism. This is important because research consistently documents Depression and Conduct Disorder as one of the most common combination of diagnoses within the juvenile justice population (Angold, Costello, \& Erkanli, 1999; Drabick et al., 2006; Liebengerg \& Ungar, 2014). Sedlak and McPherson (2010) reported that 51\% of youths reported symptoms of depression and anxiety, with $20 \%$ reporting two or more recent suicidal feelings. Additionally, 
$22 \%$ of youth in their study reported past suicide attempts, a number that is four times higher than the rate reported for youth in the general population.

\section{Common Approaches Addressing Mental Health}

Based on interviews of 1,015 youth, Burns et al. (1995) determined that out of all youth within the U.S., those with the most serious emotional disturbances were only receiving services within the juvenile justice system and were not being served by other agencies. Furthermore, research has found that youth within the juvenile justice system report low levels of mental health services, and that the juvenile justice system often provided the first mental health support system that many youth with serious problems experience (Burns et al., 2003; Liebenberg \& Ungar, 2014). It has become apparent that juvenile offenders are not receiving the mental health supports they need prior to their interaction with the juvenile justice system. This highlights the need for further research to determine which services are the most beneficial for youth in the juvenile justice system.

Because of the fluctuating definition of mental health within the literature, it is not surprising that research supporting mental health approaches within the juvenile justice system is lacking. It is also important to note that within this literature mental health services for youth who are involved in the juvenile justice system often do not identify a minor's delinquent status but rather focus on the diagnosis (Burns et al., 2003). Researchers have begun to address these concerns by examining the various approaches that court systems have taken throughout the years, highlighting approaches that have begun to be shown as effective, and focusing on the

need to determine a standardized evidence-based approach for juvenile justice facilities (Burns et al., 2003). 
Cocozza and Skowyra (2000) reported that two major approaches were commonly discussed within the literature regarding the types of services juvenile justice facilities offered. The first approach is to make more secure beds available within the mental health system in order to transfer youth back and forth between the mental health system and the juvenile justice system. However, this approach places a substantial financial burden on the juvenile justice system, with reports indicating that states spend an average of $\$ 7.1$ million a day keeping youth in residential facilities (Justice Policy Institute, 2009). Because of this additional financial burden, juvenile courts have begun to form partnerships with community-based treatment programs instead of transferring them back and forth to residential facilities. (Development Services Group, 2011).

These partnerships have aided in the creation of the second common approach taken by the juvenile corrections system, which is to provide a continuum of mental health services within the correction system. Cocozza and Skowyra (2000) determined that a collaborative continuum approach was preferable to transferring patients between facilities as it allows for easier care after youth complete their involvement with the juvenile justice system, highlighting the importance of all agencies being involved in the planning, training, and delivery of services. Furthermore, unlike transferring youth between facilities, the collaborative care model has been shown to be a cost-efficient strategy (Goodrich et al., 2013). There is significant variability in implementation of the system of collaborative care across juvenile court systems. Within that range, three successful strategies have been described.

The first strategy involves wraparound programs. Wraparound programs exemplify this collaborative continuum approach, as they use a managed care model that is tailored to each individual. These programs often offer individualized, youth-centered, family-focused, 
community-based, and culturally competent mental health services though a strength-based approach (Burns et al., 2003; Development Services Group, 2011; Kamradt, 1998). These programs support the idea that a family's involvement in the treatment process in instrumental, and that focusing on a family's strengths, learning about its culture, and building on the natural supports that exist within the family, the neighborhood, and the community are the most effective way to approach treatment. Furthermore, these programs highlight the importance of listening and learning from family members to identify the needs of the youth as well as areas of support to create an individualized treatment program for each youth. Lastly, wraparound programs emphasize establishing clear goals for the youth and the family that can be measured and evaluated to determine progress toward meeting those goals.

Wraparound programs provide a variety of supports for youth and their families, including a care coordinator who assesses and determines the needs of the youth, assists in identifying and coordinating services to meet those needs, and monitors the implementation of the individuals' mental health or substance abuse counseling (Burns et al., 2003; Kamradt, 1998). Care coordinators within the wraparound programs often have relatively low caseloads (e.g., 8-10 youths and their families) in order to provide more support to every aspect of the youth's case. An important part of the coordinator's role is to ensure that youths' services are not duplicated by different agencies but rather are supplemented by each other (Burns et al., 2003). Furthermore, wraparound programs typically have a 24-hour crisis intervention team consisting of psychologists and social workers trained to intervene in family crises that may otherwise result in the youth being removed from the home, their school, or community. Wraparound programs also use a variety of informal services including community mentors and programs, family members, and religious organizations - supports that will be available to the youth and 
their family after they complete the formal programming. These programs have had encouraging outcomes, reducing residential treatment by $60 \%$ and inpatient hospitalization by $80 \%$ (Kamradt, 1998). However, all studies indicate that more research needs to be done to determine the true efficacy of these programs.

The second strategy that uses a collaborative continuum of services is the development of mental health courts. Mental health courts are specialized courts that combine court supervision with community-based treatment services instead of a jail or prison sentence (Almquist \& Dodd, 2009). These courts provide services through formal links with community service providers, allowing youth to receive counseling, medication, and case management services (Cocozza \& Schufelt, 2006). Mental health courts have been widely used across the nation within adult courts. However, juvenile courts have been more hesitant to adopt this approach, as there is little research regarding how successful they are in reducing recidivism, and even less research regarding how effective they are for juveniles. As of 2010, there were approximately 12 juvenile mental health courts operating throughout the nation, compared to more than 250 mental health courts that exist within adult court systems (Cocozza \& Schufelt, 2006; Council of State Governments Justice Center, 2008; Development Services Group, Inc., 2010).

Although these courts continue to increase in popularity, there is a lack of agreement between courts regarding who is the target population, what charges courts will accept, how long youth should be in the program, and what type of supervision these minors should receive. However, when the juvenile court judges were surveyed, they have general commonalities. Juvenile mental health courts supervise fairly small caseloads of youths for between 10 and 18 months, with caseload sizes ranging anywhere from 10 to 75 youths (Cocozza \& Schufelt, 2006; Development Services Group, Inc., 2010). Many courts have no formal exclusionary criteria with 
respect to charges, but the mental health criteria are more restricted in order to provide services to youth with the greatest mental health needs. Around one-half of the juvenile mental health courts restrict eligibility to include youth with the most serious mental illnesses in their programs, such as schizophrenia, mood disorders, or comorbid concerns, and often exclude youth who only have a more common diagnosis of Conduct Disorder or Oppositional-Defiant Disorder (Cocozza \& Schufelt, 2006). These courts focus on increasing participants' adherence to therapeutic treatment as well as decreasing future involvement in the juvenile justice system, using existing community-based services (Development Services Group, Inc., 2010).

A third approach called the intensive supervision program, also known as intensive probation, has been modeled from a combination of wraparound programs and mental health courts and has been implemented sparsely with adults and even more sparsely with youth (Weinrath \& Donatelli, 2015). Intensive supervision programs focus on providing an individual with a higher level of surveillance during the probation term, often resulting in higher costs for the court due to surveillance methods and length of stay in jail (Weinrath \& Donatelli, 2015). Although these programs have been supported in the adult literature (Lowenkamp et al., 2010; Petersilia \& Turner, 1993), the evidence supporting intensive probation for youth is limited and results of these studies are not strong (Aos, Miller, \& Drake, 2006; Greenwood \& Turner, 2009). However, Weinrath and Donatelli (2015) suggest that more research needs to be done on intensive probation for youth to fully determine the effectiveness of these programs. The purpose of this study was to examine the influence of mental health and alcohol or substance abuse services on recidivism within an intensive supervision program. 


\section{Substance and Alcohol Use in the Juvenile Justice System}

As research on juveniles' mental health concerns have revealed high rates of substance abuse (Cocozza \& Skowyra, 2000; Deas, 2006; Shufelt \& Cocozza, 2006), researchers are beginning to examine rates of substance use among juvenile offenders. However, Cocozza and Skowyra (2000) determined that research regarding rates of substance and alcohol use within the juvenile justice population is extremely limited, with studies often examining regional statistics, only looking at incarcerated youth, and relying on retrospective self-reports to gather information. Recent research consistently looks at substance use within the juvenile justice system in terms of substance use disorders, while ignoring youth whose substance use patterns may be maladaptive but do not qualify as disorders. Researchers who have examined this disparity within the general population have consistently found between 5 and $10 \%$ of their participants meet criteria for a substance abuse diagnosis, but up to $31 \%$ of their participants displayed only 1 or 2 of the necessary symptoms and did not meet criteria (Lewinsohn, Rohde, \& Seeley, 1996; Harrison, Fulkerson, \& Beebe, 1998; Pollock \& Martin, 1999). Researchers have also determined that youth who display 1 or 2 symptoms of a substance abuse disorder are more likely to develop a disorder at a younger age and have a high probability of meeting further criteria as they get older (Grant, Stinson, \& Harford, 2001). These results show the importance of detecting and monitoring all levels of substance use among youth, rather than focusing solely on diagnosed disorders.

Surveys have shown that rates of alcohol use among youth in the general U.S. population remain high, but have decreased since 2003 (CDC, 2015a; U.S. Department of Health and Human Services, 2004). Historically, alcohol has been reported as the most common substance used by youths, with rates increasing from 78\% in 2000 to 83\% in 2003 (Grunbaum et al., 2004; 
Johnston et al., 2004; US Department of Health \& Human Services, 2004). However, rates of alcohol use more recently has been reported between $52.2 \%$ and $63.2 \%$ in 2013 , indicating a decrease in rates of alcohol use by youths since 2003 (CDC, 2015a).

Additionally, studies have shown high rates of illicit substance use among youth who were heavy users of alcohol. The National Household Survey conducted in 2004 found that $64.5 \%$ of youths aged 12 to 17 who were heavy users of alcohol also used illicit substances, compared to only $5.1 \%$ of youths who did not drink (U.S. Department of Health \& Human Services, 2004).

A survey published in 2014 reported that $10.2 \%$ of youth in the general population reported using any illicit drugs within the past month, which was a decrease from the $11.6 \%$ of youth who reported using illicit drugs within the past month in 2002 (Center for Behavioral Health Statistics and Quality, 2015). Similarly, rates of marijuana use have decreased since reports in 1997. In 2013, marijuana was the most commonly used illicit drug among youth, with $80.6 \%$ of youths who had used illicit drugs reporting having marijuana (U.S. Department of Health and Human Services, 2014). Additionally, the CDC's national Youth Risk Behavior Survey (2015b) indicated that rates of marijuana use among youths in $9^{\text {th }}$ through $12^{\text {th }}$ grade peeked in 1997 at $47.1 \%$, but since has decreased to $38.6 \%$ in 2015 .

Less is known about current rates of alcohol and substance use among youth involved in the juvenile justice system. Much of the research on youth within the juvenile justice system has looked at specific disorders rather than examining overall rates of substance use. However, the rates reported in the general population can be assumed to be modest estimates of rates of substance abuse within the juvenile justice population. National Institute on Drug Abuse (1995) found rates as high as $87.7 \%$ of incarcerated youth reporting alcohol use at least once. This 
demonstrates a higher percentage of alcohol use within youths in the juvenile justice system than is reported in the general population. National arrest data from the Uniform Crime Reports indicate that juveniles arrested for drug abuse violations between 1993 and 2002 increased 59\%. Of these arrests, $78 \%$ of youth reported being alcohol or drug involved at the time of their arrest (National Center on Addiction and Substance Abuse, 2004; Snyder, 2004). Furthermore, Beck, Kline, and Greenfeld (1988) reported rates of illicit substance use by juvenile offenders as high as $82.7 \%$. These researchers found that the most commonly used illicit substances were marijuana (56.4\%), followed by hallucinogens (17.0\%), inhalants (10.7\%), and cocaine (8.4\%). A more recent study by the Washington DC Metropolitan Area Drug Study (National Institute on Drug Abuse, 1995) found that 57.8\% of the incarcerated juveniles reported using illicit substances at some point in their life, with $49.5 \%$ reporting they used illicit substances within the past year, whereas only $20.0 \%$ of the 12 - to 17 -year-olds within the general public reported illicit substance use.

Substantial links between substance abuse and mental health diagnoses have been established, with an estimated $61 \%$ of youth with a mental health disorder who are involved in the juvenile justice system also meeting the criteria for a substance use disorder (Schufelt \& Cocozza, 2006). These youth often have a higher level of mental health needs than juvenile offenders who do not have a co-occurring substance use disorder (Deas, 2006). Co-occurring substance use and mental health disorders have been found most frequently with disruptive disorders or mood disorder diagnoses such as anxiety or depression (Armstrong \& Costello, 2002; Deas, 2006; Grisso, 2008; Schufelt \& Cocozza, 2006), with up to $35 \%$ of youth with depression and $44 \%$ of youth with anxiety reporting a comorbid substance use disorder (Center for Behavioral Health Statistics and Quality, 2015; Deas, 2006; Grisso, 2008). Substance abuse 
disorders are also commonly diagnosed with a Conduct Disorder or Oppositional-Defiant Disorder, with prevalence rates between 50\% and 60\% (Armstrong \& Costello, 2002; Deas, 2006). The relationship between Conduct Disorders and Substance Abuse Disorders appears to be highly reciprocal. It has also been reported that using substances makes it four times more likely that a youth will receive a disruptive behavior diagnosis such as Conduct Disorder or Oppositional-Defiant Disorder (Armstrong \& Costello, 2002), but Conduct Disorder usually precedes the development of a substance use disorder (Deas, 2006).

\section{Common Approaches Addressing Substance Use}

Although research has indicated that many youths entering the juvenile justice system are known to have substance abuse problems (Beck, Kline, \& Greenfeld 1988; Cocozza \& Skowyra, 2000; National Institute on Drug Abuse, 1995; Shufelt \& Cocozza, 2006), research suggests that most juvenile facilities do not provide onsite substance abuse treatment services to residents (Office of Applied Studies, 2000). Due to these challenges, little is known about the substance abuse treatment experiences of youth involved in the juvenile justice system.

However, some research studies examining substance abuse treatment programs focus on referrals from the juvenile and criminal justice systems as a subset of the populations studied. National data for publicly funded substance abuse treatment programs show that $55 \%$ of male admissions and 39\% of female admissions are referred from the adult justice system (Chassin, 2008). Furthermore, Stevens et al. (2003) reported that the majority of youths entering substance abuse treatment programs is referred from the juvenile justice system. Making this process even more complicated within the juvenile justice setting, research has found that unlike adult mental health and substance abuse programs, substance abuse agencies for youth require them to 
complete substance abuse treatment and achieve a period of abstinence before they have access to a mental health evaluation and treatment (Priester et al., 2016).

Studies suggest that not all referred youth are receiving treatment. Johnson et al. (2004) reported that only $48 \%$ of youth involved in the juvenile justice system who were referred to substance abuse treatment ever receive services. Researchers have begun to look at perceived barriers to substance abuse treatment among youth in the juvenile justice system, and report that the most commonly reported barrier is the youth's belief that the problem would go away without outside help (Abram et al., 2008; Johnson, Stiffman, Hadley-Ives, \& Elze, 2001). However, one of the major barriers to receiving substance abuse treatment among youth in the juvenile justice system may be as a result of structural inequalities that exist. Priester et al. (2016) has shown that there is a lack of openings in programs where youth can receive substance abuse services, as well as in inpatient services due to facilities being regularly at capacity. Furthermore, these researchers highlighted other structural barriers to receiving treatment beyond availability that include service location, organizational configurations for entry points and how services are provided, financial barriers, and racial and ethnic disparities in screening and identification of concerns.

One approach aimed to reduce substance use within the juvenile justice system is the juvenile drug court. This approach has become widespread, with nearly 500 juvenile drug courts being implemented across the United States as of 2007 (Bureau of Justice Assistance Drug Court Clearinghouse, 2007). Similar to the processes of mental health courts, specialists within juvenile drug courts collaborate closely with other criminal justice professionals as well as drug treatment professionals in the hopes of improving the outcomes for youth dealing with substance use problems (Sheidow, Jayawardhana, Bradford, Henggeler, \& Shapiro, 2012). Furthermore, drug 
courts employ practices such as requiring youth to appear frequently before the same drug court judge, providing intensive supervision of substance use as well as behavior at home, school, and within the community, and administering sanctions or rewards based on drug screens and behavioral reports.

Research on the effectiveness of juvenile drug courts is sparse. Henggeler et al. (2006) examined the effectiveness of drug courts for youth, and compared their effectiveness with family courts. They found that drug courts were more effective at decreasing substance use and criminal activity, and that when evidence-based treatments were integrated into drug courts, substance use rates were lowered even more. However, Sheidow et al. (2012) found that although the integration of evidence-based treatments was found to be cost-effective in decreasing offender substance use and delinquent behavior, a majority of juvenile drug courts does not use evidence-based treatments. Taken together, these results suggest that although evidence-based treatments exist for decreasing substance use and deviant behavior, juvenile court systems have not incorporated them into the current system of care.

Much of the literature does not distinguish between substance use and substance abuse disorder, which prevents juvenile court systems from understanding the true prevalence of substance use among youth. Furthermore, the limited research on substance abuse treatments and their effectiveness within the juvenile justice system prevents court systems from understanding how best to help these youth. These gaps in the literature call for additional research to be conducted, which will allow the juvenile justice system to employ evidence based treatments for all youth struggling with substance abuse issues while under the supervision of the court. 


\section{Rural Communities}

Since 2005 and the economic recession in the United States, rural communities have experienced large losses in their educational and health services as well as employment (BeebeFrankenberger \& Goforth, 2014). These changes have resulted in several challenges, such as poverty, access to mental health services, and substance use for individuals living in rural communities. In 2010, nearly 8 million people living in rural areas had incomes below the poverty threshold (Economic Research Service, 2012). About one-fifth of youth in poverty live in rural communities, and experience greater challenges than their urban counterparts as they are more isolated and have limited access to quality mental health services (Beebe-Frankenberger \& Goforth, 2014). As a result of poverty, high unemployment, and limited access to services, people living in rural communities are more likely to experience stress, as well as more social stigma about seeking mental health care due to the lack of anonymity in rural communities (Beebe-Frankenberger \& Goforth, 2014; Gustafson et al., 2009). Additionally, rural youth are at a higher risk for alcohol and substance use than urban youth (Beebe-Frankenberger \& Goforth, 2014). Despite high prevalence, $20 \%$ fewer rural youth access treatment for mental health concerns compared to their urban counterparts (Lendardson, Ziller, Lambert, Race, \& Yousefian, 2010). This is not surprising, as research has shown that accessing treatment is more difficult for rural families. Rural families receive fewer specialized services, poorer quality of care, and use a greater proportion of their income on healthcare services (Beebe-Frankenberger \& Goforth, 2014). The combination of these factors indicate that rural youth who experience mental health and substance use are qualitatively different than youth in an urban or suburban setting.

Historically, substance use by youth has been framed as an urban, primarily inner-city, problem. Although prevalence of substance use was lower among rural youth than urban youth 
until 1989, more recent data suggest that this is no longer the case (Ruiz et al., 2005). The National Household Survey on Drug Abuse (Office of Applied Studies, 2000) reported that $18.2 \%$ of rural youth and $18.8 \%$ of urban youth between the ages of 12 and 17 indicated they had tried drugs within the past year. Furthermore, Center on Addictions and Substance Abuse (2000) found that when rural and urban eighth graders were compared, rural eighth graders are $34 \%$ more likely to smoke marijuana, 29\% more likely to drink alcohol, and 104\% more likely to use amphetamines and methamphetamines than youth from urban communities. These data suggest that although rural and urban youth report similar rates of drug use overall, rural youth report drug use earlier in life. Youth reporting higher rates of drug and alcohol use earlier in life present a unique challenge for the rural juvenile justice systems, as Loeber et al. (2000) reported that the earlier the age of onset of substance use, the greater the likelihood of severe or chronic offending.

Mental health concerns have been found to commonly co-occur with substance use (Center for Behavioral Health Statistics and Quality, 2015; Deas, 2006; Grisso, 2008). Although researchers have shown that between $62 \%$ and $95 \%$ of youth entering substance abuse facilities have at least one comorbid mental health disorder (Center for Behavioral Health Statistics and Quality, 2015; Deas, 2006; Grisso, 2008), data comparing rural to urban youth who have both substance use and mental health problems is more limited. Additionally, Ruiz et al. (2005) state that results from studies that examine these differences are mixed, and when differences do exist, they are often slight and perhaps clinically meaningless.

Delinquency studies have typically focused on urban areas, but research on rural communities and delinquency has begun to surface. Osgood and Chambers (2003) examined arrest rates for juvenile violence in rural counties, and found that arrest rates are lower in rural 
communities relative to their urban counterparts. Ruiz et al. (2005) examined the differences between 250 rural and 273 urban youth's substance use, mental health issues, substance abuse treatment, and juvenile justice involvement. These researchers found equal rates of substance and alcohol use within rural and urban youth, with the exception of higher rates of marijuana use among rural youth relative to urban youth. Additionally, they found similar rates of anxiety between the two groups and less severe overall general mental health and depression scores among rural youth who were enrolled in substance abuse treatment compared to their urban peers. These authors noted, however, that although these results were significant, they may not be clinically meaningful because each of the group mean scores was within the considerable and medium severity of symptoms categories, suggesting that youth within both settings experience a higher severity of symptoms than was expected. These findings indicate that youth in both rural and urban settings experience high levels of mental health symptoms. 


\section{CHAPTER II: THE CURRENT STUDY}

Substantial links between mental health concerns, substance use, and incarceration for youth have been established. Youth with severe mental health concerns are more likely than youth with less severe mental health concerns to receive mental health services through the juvenile justice system, and prevalence of mental health disorders is significantly higher among juvenile offenders than within the general community (Burns et al, 1995; Cauffman, 2004;

Schufelt \& Cocozza, 2006). Similarly, juvenile offenders experience heightened rates of substance use relative to the general population (Chassin, 2008; Shufelt \& Cocozza, 2006; Sickmund \& Puzzanchera, 2014). Furthermore, youth who have both a mental health disorder and substance abuse concerns are more likely to be involved with the juvenile justice system than their peers without comorbid concerns (Armstrong \& Costello, 2002; Schufelt \& Cocozza, 2006).

In an attempt to understand what puts adolescents at a heightened risk to be involved in the juvenile justice system, researchers have begun examining multiple factors that could influence youths' likelihood of being arrested (Fergusson et al., 1996). Much of this research has focused on identifying how these factors relate to one another to put the adolescent at a higher risk to offend. Furthermore, other studies have examined which factors put youths at a lower risk of being involved in the juvenile justice system, and urge the juvenile justice system to put specific supports in place to reduce recidivism (Sickmund \& Puzzanchera, 2014). However, overall there is relatively little that is known regarding how services are organized and delivered, and whether or not they make a difference (Coccoza \& Skowyra, 2000).

The current study attempts to provide answers to some of these questions by analyzing the role that successfully completing mental health and substance abuse services plays in 
determining further contacts with the juvenile justice system. Specifically, the current study examined the associations among mental health concerns, mental health treatment, and recidivism for youth in a geographically large, sparsely populated Midwestern county.

Furthermore, this study examined how substance use and substance abuse treatment was related to recidivism rates for youth in a rural community. Finally, the current study examined how mental health and substance abuse treatment compliance was related to further contacts with the judicial system. 


\section{CHAPTER III: METHOD}

\section{Overview}

Data were collected from the juvenile court system in a geographically large, sparsely populated Midwestern county. According to the Illinois Department of Juvenile Justice Summary of State Fiscal Year 2015 Admissions report, 1493 youth were admitted into detention facilities during 2015. Of these youth, $68.9 \%$ were Black, $19.0 \%$ were White, $11.9 \%$ were Hispanic, $0.2 \%$ were Asian, and $0.1 \%$ were American Indian. The most common ages at admission into the juvenile justice system was either $17(31.4 \%)$ or $16(21.9 \%)$ years, and youth were overwhelmingly male $(93.1 \%)$. The county examined in this study made up $0.4 \%$ of the youth admissions within this state. No data were available about the number of arrests of youth that this county had made during that timeframe.

Recent statistics for this county show that since 2006, rates of youth living in poverty increased from $13.6 \%$ to $18.1 \%$ in 2012 (Voices for Illinois Children, 2015). Rates of youth living in families with incomes below $50 \%$ of the poverty level stayed fairly consistent, with $7.6 \%$ of children living in deep poverty in 2006 and $7.2 \%$ in 2012 (Voices for Illinois Children, 2015). Adult unemployment rates increased, as 4.4\% of the population was unemployed in 2006 and $7.1 \%$ reported unemployment in 2014 (Voices for Illinois Children, 2015). Additionally, $23.0 \%$ of households with youth in this county received supplemental nutrition assistance program benefits in 2012 (Voices for Illinois Children, 2015).

This county recognized the importance of addressing barriers to mental health services for youth, and initiated a countywide effort to improve the system of care for children's mental health (Huber et al., 2016). Starting in 2011, the community slowly implemented a 4-tiered public health model of youth's mental health across the county with an interconnected system 
approach to address the needs identified through a needs assessment. As a result of this intervention, the juvenile justice system adjusted some of the practices surrounding mental health and substance use, including annual screening, the creation of a juvenile justice liaison to assist with connecting youth and families with mental health and substance abuse services, and a more inclusive exchange of information form. Furthermore, the system adopted the intensive supervision program to address youth's mental health and substance. Results of the intervention indicated a substantial decrease in the number of youth entering the juvenile justice system, as well as an overall reduction in the percentage of positive mental health and substance abuse screens among youth throughout the county.

\section{Participants}

Archival probation and court records of all youth serviced by the county court system from 2010 to 2015 were examined. These juvenile records were obtained from the presiding judge. At the request of the judge, court services provided a comprehensive list of all juvenile cases served between 2010 and 2015. Cases were excluded from analysis for the following reasons: (1) The youth was no longer residing in the county, (2) The case concerned behavior of the parent, rather than the youth (e.g., custody), (3) The youth aged out of the juvenile court system. All participants remaining after exclusionary criteria were examined were included in the study. Data from a total sample of 77 participants were examined. As discussed below, this sample had sufficient power to detect a large effect size.

\section{Materials}

Electronic probation files were provided by the County probation services office. Once the probation records were de-identified by the judge's clerk, access to these electronic probation files was granted to the researchers. Furthermore, the circuit court clerk selected corresponding 
court records and the probation records clerk selected the corresponding paper probation records for the researchers to examine.

When scores on the Youth Assessment Screening Instrument (YASI) were included in the probation records, these scores were examined. The YASI is a screening tool that provides an estimation regarding the juvenile's risk of reoffending (e.g., high, moderate, low), as well as recommendations regarding services that the juvenile needs (Orbis Partners, 2007). This county used the YASI to determine if the youth was required to receive a mental health or substance abuse evaluation as a part of their probation order. For some cases, the YASI was included in the probation file, whereas in others the only evidence of YASI results was the requirement of receiving a mental health or substance abuse evaluation as a probation term.

Furthermore, information regarding the services that the juvenile received was extracted from the problem areas and goals section of the YASI results to indicate not only which services the youth received but also as a way to track progress within those services. Information that was gained from these results relating to mental health services, substance use, and substance abuse treatment were noted along with the date that those problem areas and goals were indicated. This information was used to determine if the youth had mental health or alcohol/substance abuse concerns, and to provide information about the youth's compliance to treatment.

Attendance records from mental health and substance abuse counseling were examined when they were available. Reports from counseling centers provided information about whether the juveniles attended sessions, skipped sessions, and rescheduled sessions. These reports also contained information regarding which type of services were received by the youth, the intensity of those services, and the successful or unsuccessful completion of counseling services. 
Finally, results from drug screens were examined. Paperwork from drug screens and their corresponding results were examined from probation files. This paperwork provided information regarding frequency of substance use, and which type of substances were being used.

Information that was gained from this paperwork was noted along with the date the drug screen was given and the date the results were received from the lab.

\section{Procedure}

After receiving IRB approval for the project and completing ethics training, researchers read through both the de-identified probation and court files, extracting dates, charges, professional contacts regarding the minor, parental incarceration status, and information regarding the juvenile's social, behavioral, and educational outcomes. Information regarding mental health services, substance use, and substance abuse treatment was coded.

This information was extracted by six undergraduates and three graduate students and placed into separate Excel sheets for each participant. Each of the research assistants involved received standardized training on how to extract this information from the primary researcher, with individualized follow-up training until the trainee reached a consensus criterion with the primary researcher. A second researcher recoded every 5th case independently in order to determine interrater reliability ( $20 \%$ of cases) for coding. Furthermore, to ensure a consensus of coding, for $80 \%$ of participants the court file and probation file were coded by different researchers. The training manual is available in Appendix A.

\section{Probation Logs}

Probation logs were examined to extract information about the activities of professionals involved with the juvenile or information about the juvenile's mental health, substance use, and services they received. Furthermore, any positive or negative developments related to the 
juvenile's functioning was coded for analysis. Similarly, any additional charges, court decisions, and drug screening results were extracted and coded as a part of the contact description.

Each court charge was coded and entered separately for each youth. The researchers also noted the number of counts per charge. These charges were coded into general categories: Status offenses (i.e., curfew violations, truancy, running away from home, underage purchase or possession of alcohol, underage consumption of alcohol), violent crimes, (i.e., murder, kidnapping, armed robbery ), sex crimes (i.e., indecent exposure, sexual assault, prostitution, solicitation, rape, statutory rape), property crimes (i.e., theft, burglary, robbery, larceny, shoplifting, arson, vandalism, criminal trespassing), drug crimes (i.e., unlawful possession of drug paraphernalia, drug possession, drug manufacturing and cultivation, drug trafficking and distribution), and aggravated crimes (i.e., aggravated assault, battery, assault with a deadly weapon, robbery). Additionally, the charges were coded to identify the type of charge (e.g., diverted, misdemeanor, felony, dismissed).

\section{Court Records}

Court files were examined and additional information regarding the juvenile's functioning that was not included in probation logs was extracted and coded. Information available in the court records was largely redundant with the information that is available in the probation logs. Therefore, one researcher examined the court records and a second researcher examined the probation logs to check the work of each researcher, ensure accurate coding, and update the excel spreadsheet with information not available in the probation logs. This information was extracted and coded through the same process as the probation logs. Furthermore, charges or arrests that did not result in probation were extracted and coded. Similarly, information regarding the juvenile's initial contact with the system was extracted and any information that was 
available about the adolescent and their involvement with the system prior to their probation file was extracted and coded. The youth's month and year of birth was also extracted. 


\section{CHAPTER IV: RESULTS}

After probation and court records were examined, data were extracted and coded for evidence of alcohol/substance use, mental health concerns, alcohol/substance abuse treatment, mental health counseling, compliance with treatment, and further contacts with the juvenile justice system for each participant. Alcohol/substance use was coded as 0 for no history of alcohol/substance use, and 1 for a history of alcohol/substance use. Mental health concerns were coded as 0 for no evidence of a history of mental health concerns, and 1 for a history of mental health concerns. Alcohol/substance abuse treatment was coded as a 0 for no alcohol/substance abuse treatment, and 1 for alcohol/substance abuse treatment. Mental health counseling was coded as a 0 for no mental health counseling, and 1 for mental health counseling. Lastly, recidivism was coded as the number of charges that a youth received after their initial charge.

To capture compliance with both alcohol/substance abuse treatment and mental health counseling, the frequency of positive and negative statements made about a youth's participation in treatment was coded. For example, if records indicate that the youth's attendance at counseling was sporadic, one tally would be placed in the negative statements column. However, if later on in the record it was indicated that the youth attended regularly, one tally was placed in the positive statements column. The ratio of these statements was computed to form a compliance-with-treatment variable. This variable was computed by dividing the number of positive statements made about treatment (i.e., they are going, treatment is going well, successfully discharged from program) by the overall number of statements made about treatment. The compliance-with-treatment index is available in Appendix B. 


\section{Results}

This sample contained 77 cases, including 57 male youth (74.03\%) and 20 female youth (25.97\%). The average age of youths at their entrance into the juvenile justice system was 14.87 years $(\mathrm{SD}=2.00)$, with the youngest individual being 8 years and the oldest being 18 years. In this sample, $80.52 \%$ of youths were white, $7.79 \%$ of youths were black, and $11.69 \%$ of unknown race. Of the total cases, $49.35 \%$ of youth were identified as having a mental health concern ( $81.58 \%$ male, $84.21 \%$ white, average age of 14.68 years), and $35.06 \%$ of youth were identified as receiving mental health treatment ( $96.30 \%$ male, $92.59 \%$ white, average age of 14.19 years). Furthermore, $53.25 \%$ of youth were identified as having an alcohol/substance abuse concern (80.49\% male, $82.93 \%$ white, average age of 15.46 years), and $35.06 \%$ of youth were identified as receiving alcohol/substance abuse treatment (88.89\% male, $96.30 \%$ white, average age of 14.85 years).

To examine interrater reliability, $20 \%$ of cases were recoded and intra-class correlations were computed. The intra-class correlations for identifying mental health concerns, mental health treatment, substance abuse concerns, substance abuse treatment, and recidivism reflected perfect agreement. To examine interrater reliability for identifying compliance statements, $20 \%$ of the cases receiving mental health and substance abuse services were recoded and intra-class correlations were conducted. The intra-class correlations for mental health, $r(13)=1.00$, and substance abuse treatment compliance statements, $r(13)=.98$, were both within the excellent range.

To test my hypotheses that higher mental health and substance abuse concerns would predict higher recidivism, two separate hierarchical regressions were conducted. In the first hierarchical regression, mental health concerns and mental health treatment were examined as 
predictors of recidivism. Having mental health concerns significantly predicted recidivism. When receiving mental health treatment was introduced into the analysis, having mental health concerns was no longer a predictor of recidivism, but receiving mental health treatment significantly predicted recidivism. Results can be seen in Table 1 . These results supported my first hypothesis, such that having mental health concerns predicted recidivism. However, there was no evidence that receiving mental health treatment reduced the likelihood of recidivism.

The second hierarchical regression examined the relation between alcohol/substance abuse concerns, alcohol/substance abuse treatment, and recidivism. Having an alcohol/substance abuse concern significantly predicted recidivism. When receiving substance abuse services was introduced into the regression, having an alcohol/substance abuse concern was no longer a significant predictor of recidivism, but receiving alcohol/substance abuse treatment significantly predicted recidivism. Results can be seen in Table 2. The pattern of these results was consistent when youth who only had alcohol use concerns were removed $(N=4)$ for both substance abuse concerns alone, substance abuse concern with substance abuse treatment, and substance abuse treatment. Results can be seen in Table 3. These results supported my hypothesis that having alcohol/substance abuse concerns would predict recidivism. However, there was no evidence that receiving substance abuse services reduced the likelihood of recidivism.

Next, to test my hypothesis that there would be a significant negative correlation between mental health and alcohol/substance abuse treatment compliance ratios and recidivism, a correlation was conducted. There was no evidence of a relation between the mental health compliance ratio and recidivism, $r(25)=.18, p=.38$, or between the alcohol/substance abuse compliance ratio and recidivism, $r(25)=.02, p=.92$. These results suggest that having a higher ratio of positive compliance with treatments was not related to lower recidivism rates. 


\section{Supplemental Analyses}

To gain a better understanding of the relation between mental health concerns and mental health treatment, a correlation was conducted to examine the relation between having an identified mental health concern and receiving mental health treatment. There was strong evidence of a relation between having a mental health concern and receiving mental health treatment, $r(75)=.74, p<.001$. Of the 38 youth with mental health concerns, $71.05 \%$ were receiving mental health treatment. Additionally, $73.68 \%$ of youth who had mental health concerns, and $85.19 \%$ of youth who received mental health treatment reoffended.

To gain a better understanding of the relation between alcohol/substance abuse concerns and alcohol/substance abuse treatment, a correlation was conducted. There was strong evidence of a relation between having an identified alcohol/substance abuse concern and alcohol/substance abuse treatment, $r(75)=.53, p<.001$. Of the 41 youth with alcohol/substance abuse concerns, $65.85 \%$ were receiving alcohol/substance abuse treatment. Additionally, $65.85 \%$ of youth with alcohol/substance abuse concerns, and $85.19 \%$ of youth who were receiving alcohol/substance abuse treatment reoffended.

Because the amount of time in the juvenile justice system influences the opportunities that youth have to reoffend, I conducted additional analyses controlling for length in the system in both hierarchical regressions. In the first hierarchical regression, total time in the juvenile justice system, mental health concern, mental health treatment, and recidivism were examined. Total time in the system significantly predicted recidivism. When having a mental health concern was introduced into the regression, both total time in the system and having a mental health concern significantly predicted recidivism. However, when receiving mental health services was introduced into the regression, having a mental health concern was no longer a significant 
predictor of recidivism, but total time in the system and receiving mental health treatment significantly predicted recidivism. Full results are available in Table 4 . This pattern was similar to that found without adding total time in the system as a control variable.

A second hierarchical regression was conducted to examine total time in the juvenile justice system, alcohol/substance abuse concerns, alcohol/substance abuse treatment, and recidivism. Total time in the system significantly predicted recidivism. When having an alcohol/substance abuse concern was introduced into the regression, both total time in the system and having an alcohol/substance abuse concern significantly predicted recidivism. Furthermore, when receiving alcohol/substance abuse services was introduced into the regression, total time in the system, having an alcohol/substance abuse concern, and receiving alcohol/substance abuse treatment all significantly predicted recidivism. Full results are available in Table 5. This pattern was different from the pattern that was found without adding total time in the system as a control variable. This new pattern suggests that regardless of the time that individuals are receiving services through the juvenile justice system or if they are receiving treatment for their alcohol/substance abuse concerns, youth who use alcohol or substances are more likely to reoffend than youth who do not use alcohol or substances. This pattern remained when controlling for race and gender in both hierarchical regressions. 


\section{CHAPTER V: DISCUSSION}

It was hypothesized that having an identified mental health concern, as well as having an identified alcohol/substance abuse concern would significantly predict recidivism. It was also hypothesized that not receiving mental health or alcohol/substance abuse treatment for these identified concerns would significantly predict recidivism. The results supported the first hypothesis that having identified mental health concerns or alcohol/substance abuse significantly predicted recidivism. However, analyses of the current data did not support the second hypothesis that not receiving treatment for either identified concern would predict recidivism. Instead, the results suggested that youth who did not receive treatment were less likely to reoffend than youth who did receive treatment. These results add to the previous results that youth's mental health and alcohol/substance abuse concerns exist on a continuum of severity, and explain why youth with mental health or alcohol/substance abuse concerns who are receiving treatment have high rates of recidivism. Additionally, they support the idea that youth who have identified mental health or alcohol/substance abuse concerns by the juvenile justice system are receiving treatment for those concerns.

The third hypothesis that having high alcohol/substance abuse treatment compliance ratios would be negatively correlated with recidivism was not supported. Similarly, the fourth hypothesis that having high mental health treatment compliance ratios would be negatively correlated with recidivism was not supported. It is possible that measuring compliance ratios by the amount of positive and negative statements made throughout the probation record is not an accurate depiction of how compliant youth within the juvenile justice system were with their mental health or alcohol/substance abuse treatment. Judicial systems that require youth to attend mental health or alcohol/substance abuse treatment may want to monitor attendance rates more 
closely, rather than receiving reports about how treatment is going from youth and their families. Future research should focus on accessing attendance records for youth to determine whether the difference between attended and missed sessions is related to recidivism.

Additionally, we found no evidence that higher ratios of mental health and alcohol/substance abuse treatment compliance were negatively correlated with recidivism. That is, more compliance with treatment of either kind was not related to lower recidivism rates. Due to the fact that a classification of compliance was created for this study since measures of compliance to treatment were not available through the court, these results suggest that a better way to track youth's progress within treatment is necessary. The limited research about the influence of receiving mental health and substance abuse services has on the likelihood that youth will reoffend indicates that successfully receiving services reduces the likelihood that youth will reoffend. However, current results did not support this finding, suggesting that the way treatment compliance was operationalized and measured in this study may not have been adequate for understanding youth's treatment compliance. Further research should be conducted to examine records and reports of mental health and alcohol/substance abuse services for youth within the juvenile justice system to get a fuller picture of attendance, progress with treatment, and compliance with homework activities.

It is important to note that many of the youth who were examined as a part of this study had ongoing cases, and reports of identified concerns, treatment, and recidivism were not available for the entirety of a youth's time involved in the juvenile justice system. Thus, it is possible that youth coded low on recidivism in this study went on to reoffend after 2015. Additionally, the data examined in this study were obtained from a juvenile justice system that began the implementation of the intensive supervision program in 2010. Implementation of new 
programs brings a period of transition in which individuals within the systems are identifying problems and solving them within organizations (Huber et al., 2016). It is likely that many of the cases within the first couple of years in this study did not receive the same type of experience within the intensive supervision program as youth who received services during the last few years. Since the individual who coordinated mental health and alcohol/substance abuse services began in 2012, future research should attempt to differentiate youth who received services during the implementation period from youth who received services after intensive probation services were fully implemented.

These results build on the limited research that has been conducted on intensive supervision programs. Previous research on intensive supervision programs have examined their efficacy with adults compared to different probation programs (Aos, Miller, \& Drake, 2006; Greenwood \& Turner, 2009). However, this research began to examine the influence of intensive supervision programs for youth receiving these services. Specifically, this research highlights the influence intensive supervision has on youth who require mental health and alcohol/substance abuse services. Results indicate that a large percentage of youth who are receiving mental health or substance abuse services within intensive supervision programs reoffend, suggesting that more intensive management of the treatment progress by probation officers and the judge may be necessary to reduce recidivism rates for youth receiving treatment. However, with more involvement by probation officers there is a higher opportunity for youth to get caught engaging in poor behavior. Although this may initially seem like a good thing, it also could result in youth getting stuck within the juvenile justice system due to additional recidivism. Youth who have less intensive monitoring by probation officers may engage in similar behaviors that go against their probation, but still have overall positive outcomes and no further recidivism. This may 
increase the amount of youth who are in the juvenile justice system who have a higher level of need, as well as increase their recidivism rates.

Although there are no known statistics about the percentage of youth who do not access treatment for their mental health or substance abuse concerns, previous literature has examined rates of youth who do receive treatment. Winstanley et al. (2012) examined how often youth generally access mental health or substance abuse services. They found that within the general community, $21 \%$ of adolescents with mental health concerns accessed treatment compared to only $14 \%$ of youth who had substance abuse concerns. These results suggest a generally low level of youth receive treatment for concerns that they have. Therefore, it is promising that only $14 \%$ of youth who had an identified mental health concern, and $18 \%$ of youth who had an identified alcohol or substance abuse concern did not access treatment for those concerns within this study. It is likely that the juvenile justice system has an opportunity to more easily provide these services for youth who have these concerns than youth who are in the general community experience.

Furthermore, these results suggest that being in treatment for mental health or alcohol/substance abuse concerns is likely different from completing treatment for those concerns. Specifically, receiving mental health treatment is a process, with participants likely going through a series of highs and lows as they begin to learn and practice new, replacement skills for their current behaviors. Successfully completing mental health treatment also can look different for different individuals, as different treatment goals are made for each individual within therapy. Moreover, the process of alcohol/substance abuse treatment is different from the process of mental health treatment. Although alcohol/substance abuse treatment has a definitive end goal of living a substance-free life, the process of being in treatment can be different for each 
individual. Similar to progress within mental health treatment, youths' progress within alcohol/substance abuse treatment may fluctuate throughout time.

The results of the supplemental analyses suggest that there is a difference between mental health concerns and alcohol/substance abuse concerns. When total time in the system was controlled for, having an alcohol/substance abuse concern and not receiving treatment still significantly predicted recidivism. This pattern of results suggests that alcohol/substance abuse alone puts one at risk for recidivism. It is possible that since using alcohol or substances as a minor is against the law in and of itself, the behavior that results in youth being identified as having an alcohol/substance abuse concern puts them at a greater risk of recidivism. Said another way, the behavior that places youth into the alcohol/substance abuse concern category is illegal and places them at a higher risk of recidivism. These results also may suggest that there is an increasing trajectory of severity of alcohol/substance use, with youth who have not been identified as needing treatment not meeting the cutoff required to receive services. It is also possible that these results could be a result of a long gap of time between being identified as having a concern and receiving treatment for these concerns.

Regardless, research has shown the lack of evidence based treatments that are used in substance abuse programs in the juvenile justice facility, as well as the lack of treatment placements that are available for specific concerns (Sheidow et al., 2012). Furthermore, literature has shown that youth with conduct disorders are a difficult population when it comes to treatment because they are often less compliant to treatment requirements (Preister et al., 2016). With this specific population being more difficult to treat than other populations, and the lack of evidence based strategies being used, it is not surprising that the effectiveness of these types of programs is lower than one would hope. 


\section{Strengths and Limitations}

This study must be interpreted in the context of a relatively homogeneous sample consisting primarily of white male youths. Although this sample was taken from a rural community, which typically has less racial diversity within the Midwest, only two racial categories were tracked within this juvenile justice system. This coding not only simplifies the racial make-up of this population, but also limits the ability to track youth of different racial categories than white or black. This sample was $74 \%$ male, which slightly over represents females compared to the juvenile justice population in the rest of the state. As a result, these findings should not be generalized to jurisdictions which service a larger proportion of males. However, much of the research that has been conducted within the juvenile justice setting takes place within more urban settings, and as such this study provides insight to the gender and racial make-up of juvenile justice settings within rural settings. That is, this study adds to the limited research that has been conducted on rural juvenile justice settings. This focus on rural youth is a particular strength of the study, as literature has shown that rural youth face more challenges around mental health, including access to care and stigma, and have different experiences with substances (Beebe-Fankenberger \& Goforth, 2014; Deas, 2006; Gustafson et al., 2009; Loeber et al., 2000; Ruiz et al., 2005)

This research was limited to a relatively modest sample size. A larger sample size would have allowed me to investigate differences between diagnoses, age, time in the system, and gender. However, due to the limited research that has been conducted within the juvenile justice setting, this study provides valuable information about the outcomes for youth with mental health or alcohol/substance abuse concerns. In many cases, juvenile court records are not available to researchers. However, I was granted access to juvenile court records for this project, which 
provided more thorough information about youth's experiences within the juvenile justice setting. In this study, I had access to a rich data set about youth offenders, consisting of probation and court records. Additionally, this study provides insight into the processes of the juvenile justice system, and provides guidance for future research to form more specific questions to examine in the future.

Given the studies five-year time-frame, not all youth began their time in the juvenile justice system at the beginning of those five years and ended all contact with the juvenile justice system when the study was complete. However, it is important to note that 43 of the 77 youth that were included in this study would have aged out of the juvenile justice system at the end of 2015 and moved to an adult system. This number does not include all youth that successfully completed probation and would never have contact with the juvenile justice system again who were not eighteen. It is possible to assume that some of the youth included in my sample reoffended after the completion of the study, whereas others ceased their contact with the juvenile justice system forever.

A final limitation of this study was that the records of the liaison who connected youth and their families to mental health and alcohol/substance abuse services were not available. It is likely that these records would offer more thorough information about the treatment that youth received, and their compliance with that treatment. This position began in 2012, and so not all youth had access to these services. However, only 29 of the 77 cases began before 2012 and did not have access to this individual when beginning mental health or substance abuse services. Future research could include information that the mental health and alcohol/substance abuse liaison has about the severity of these concerns, diagnoses, treatment attendance, and treatment outcomes. Furthermore, future research could examine if youth connected with services through 
this liaison were more likely to receive treatment, adhere and attend treatment, as well as what their recidivism rate is compared to youth who did not receive these services.

\section{Future Research}

Future research could separate out youth who received different levels of mental health and alcohol/substance abuse services to determine the association with recidivism. Based on the results of this study, it appears that youth with more severe mental health and alcohol/substance abuse concerns are more likely to receive treatment and are also more likely to reoffend. By the same logic, perhaps youth who receive more intensive services, such as a placement in an inpatient or residential facility, have different experiences from those of youth who receive less intensive services, such as outpatient services. Future research should examine the difference between recidivism rates for youth receiving these different types of services.

Similarly, future research should examine the differences in outcomes for youth by diagnosis. Previous research suggests that youth with different diagnoses have different outcomes within the juvenile justice system. Specifically, youth who ADHD, depression, and anxiety have been found to have higher re-arrest rates than youth who do not have these diagnoses (Cottle et al, 2001; Vreugdenhil et al, 2004). It would be interesting to examine the influence that intensive supervision programs has on youth with different diagnoses and different combinations of diagnoses. This type of research would inform the literature about common diagnoses within the juvenile justice system, outcomes, and the influence that intensive supervision programs has upon these outcomes.

Specifically, future research could examine the impact of the structural inequalities and barriers to treatment than these youth face. Previous research suggests that there are a large number of structural barriers for youth to receive treatment within the juvenile justice system for 
either mental health or substance abuse services (Priester et al., 2016). It may be possible to examine the quality of care that youth receive, the length of time between their referral and their entrance into treatment, and the type of treatment that is being offered to youth to determine if this is related to recidivism. This type of research would further inform the literature about the effectiveness of programs the juvenile justice system is currently providing, as well as the barriers that could be reducing the overall quality of care that individuals receive during treatment.

Additionally, future research should examine the influence of comorbid mental health and alcohol/substance abuse concerns on recidivism rates. Previous research suggests that youth who have comorbid mental health and alcohol/substance abuse concerns are more likely to reoffend than youth who have only one of these concerns (Espinosa et al., 2013; Liebenberg \& Ungar, 2014; Teplin et al., 2002; Trupin et al., 2004; Weemhoff \& Villarruel, 2011). Based on the results of this study, youth who had mental health concerns or alcohol/substance abuse concerns were more likely to reoffend than youth who did not have identified concerns. However, due to the low rate of youth who experienced both comorbid mental health and substance abuse concerns we were unable to establish a distinct group in order to examine the relation between co-occurring concerns and recidivism.

Future research could examine the relation between different individual differences and recidivism. Specifically, future research should examine outcomes for males compared to females within intensive supervision programs, as well as outcomes based on socioeconomic status, race, or household type. Additionally, future research should compare outcomes for intensive supervision programs within rural and urban communities. This type of research would 
clarify for whom intensive supervision programs are the most effective, and where these programs should be implemented in the future.

\section{Public Policy Implications}

This research has examined and isolated the current mechanisms in place to identify youth who have mental health or substance abuse concerns, as well as to monitor their treatment. Specifically, this research has highlighted the gaps that currently exist within this process, as well as a lack of a systematic way to track these concerns. Although juvenile justice systems have been tasked with the responsibility of identifying and providing treatment for mental health and substance abuse concerns (Bazemore, 1999; Sickmund \& Puzzanchera, 2014; Zang, 2015), it appears as if this responsibility has not yet become a priority. Court systems may be able to make more informed decisions regarding youths' needs, compliance, and likelihood of reoffending if they monitored mental health and substance abuse more closely. Specifically, court systems should begin to include if youth have an identified mental health or substance abuse concern for all individuals in a similar manner to general demographic information. Furthermore, courts could begin to monitor youths' attendance with treatment more closely. It would be possible to have youths' attendance to mental health or substance abuse treatment monitored by the court, such that youths and service providers were required to notify probation officers of cancelations, rescheduling, or not showing up for an appointment. Probation officers could track this information and report about how treatment is going to the judge who required evaluation and treatment in order to monitor their compliance with this condition of probation.

Furthermore, probation officers could play a larger role in ensuring youth are receiving treatment in the same way that they monitor community service hour completion. Probation officers could keep track of how many hours or sessions that youth are attending, if it is 
individual or group therapy, and how often the youth do not attend. If adherence to treatment was monitored more closely, it would be possible for probation officers to sanction youth who consistently are not attending treatment. Further collaboration between service providers and probation officers would be necessary in order for this type of system to be effective. Probation officers should request and receive regular updates or reports from services providers about how treatment is going, and which treatment goals have been met. This would also provide probation officers with information about how to link youth to community services once they complete probation in order for youth to continue to be supported.

It would be possible to create a monitoring template for these concerns to be filled out by probation officers that is connected with electronic probation logs. This would allow for more systematic tracking of youth and their mental health or substance abuse concerns across all juvenile justice facilities. Furthermore, it would ensure that all probation officers are keeping track of the same information regarding concerns and treatment progress. This type of tracking system would allow for a systematic organization of qualitative information provided by mental health and substance abuse counselors, as well as more concrete information about how treatment is going. For example, this type of tracking system may allow for probation officers to keep track of drug screenings that youth complete during their alcohol or substance abuse treatment programs, results of drug screens, any screening data that is collected about the youth's general mental health or substance abuse concerns, and the overall progress that the youth is making toward their treatment goals. A monitoring template would also allow for judges to quickly be brought up to speed about progress youth are making in treatment in order to make more informed decisions regarding compliance to probation. 


\section{REFERENCES}

Aalsma, M. C., White, L. M., Lau, K. S. L., Perkins, A., Monahan, P., \& Grisso, T. (2015). Behavioral health care needs, detention-based care, and criminal recidivism at community reentry from juvenile detention: A multistate survival curve analysis. American Journal of Public Health, 105, 1372-1378.

Abram, K. D., Paskar, L. D., Washburn, J. J., \& Teplin, L. A. (2008). Perceived barriers to mental health services among youth in detention. Journal of the American Academy of Child and Adolescent Psychiatry, 47, 301-308. doi: 10.1097/CHI.0b013e318160b3bb.

Almquist, L, \& Dodd, E. (2009). Mental health courts: A guide to research-informed policy and practice. Council of State Governments Justice Center, http://www.calcasa.org/wpcontent/uploads/2009/09/Mental-Health-Courts-A-guide-to-policy-and-practice.pdf.

American Psychiatric Association. (2013). Diagnostic and Statistical Manual of Mental Disorders (5 ${ }^{\text {th }}$ ed.). Washington D.C: American Psychological Association.

Angold, A., Costello, E. J., \& Erkanli, A. (1999). Comorbidity. Journal of Child Psychology and Psychiatry and Allied Disciplines, 40, 57-87.

Aos, S., Miller, M., \& Drake, E. (2006). Evidence-based public policy opinions to reduce further prison construction, criminal justice costs and crime rates. Washington State Institute for Public Policy report. Olympia, CA: Washington State Institute for Public Policy.

Armstrong, T., \& Costello, E. (2002). Community studies on adolescent substance use, abuse, or dependence and psychiatric comorbidity. Journal of Consulting in Clinical Psychology, 70, 1224-1239. doi: 10.1037//0022-006X.70.6.1224 
Baron, R. M., \& Kenny, D. A. (1986). The moderator-mediator variable distinction in social psychological research: Conceptual, strategic, and statistical considerations. Journal of Personality and Social Psychology, 51, 1173-1182. doi: 10.1037/0022-3514.51.6.1173

Bazemore, G. (1999). The fork in the road to juvenile court reform. The Annals of American Academy of Political and Social Sciences, 564, 81-108.

Beck, A. J., Kline, S. A., \& Greenfeld, L.A. (1988). Survey of youth in custody, 1987. BJS Special Report, https://www.ncjrs.gov/pdffiles1/Digitization/113365NCJRS.pdf.

Beebe-Frankenberger, M. \& Goforth, A. N. (2014). Best practices in providing school psychological services in rural settings. In Harrison, P. L. \& Thomas, A. ( $5^{\text {th }}$ Ed.), Best practices in school psychology: Foundations. (pp. 143-156). Bethesda, MD: NASP Publications

Bureau of Justice Assistance Drug Court Clearinghouse. (2007). Drug court activity update: Composite summary information. Washington, DC: American University. https://socialwork.utexas.edu/dl/files/cswr/institutes/ari/pdf/DrugCourtActivityUpdate200 7.pdf.

Burns, B., Costello, E., Angold, A., Tweed, D., Stangl, D., Farmer, E., \& Erkanli, A. (1995). Children's mental health service use across service sectors. Health Affairs, 14, 147-159. doi: 10.1377/hlthaff.14.3.147

Burns, B. J., Howell, J. C., Wiig, J. K., Augimeri, L. K., Welsh, B. C., Loeber, R., \& Petechuk, D. (2003). Treatment, services, and intervention programs for child delinquents. Office of Juvenile Justice and Delinquency Prevention Bulletin, https://www.ncjrs.gov/pdffiles1/ojjdp/193410.pdf. 
Cauffman, E. (2004). A statewide screening of mental health symptoms among juvenile offenders in detention. Journal of the American Academy of Child and Adolescent Psychiatry, 43, 430-39. doi: 10.1097/00004583-200404000-00009

CDC. (2015a). Trends in the prevalence of alcohol use national YRBS: 1991-2015. Division of Adolescent and School Health, http://www.cdc.gov/healthyyouth/data/yrbs/pdf/trends/2015_us_alcohol_trend_yrbs.pdf.

CDC. (2015b). Trends in the prevalence of marijuana, cocaine, and other illegal drug use national YRBS: 1991-2015. Division of Adolescent and School Health, http://www.cdc.gov/healthyyouth/data/yrbs/pdf/trends/2015_us_drug_trend_yrbs.pdf.

Center for Behavioral Health Statistics and Quality. (2015). Behavioral health trends in the United States: Results from the 2014 national survey on drug use and health. Retrieved from http://www.samhsa.gov/data/.

Center on Addictions and Substance Abuse (CASA). (2000). No place to hide: Substance abuse in midsize cities and rural America. New York: Columbia University Press.

Chassin, L. (2008). Juvenile justice and substance use. Future of Children, 18, 165-183. doi: 10.1353/foc. 0.0017

Cocozza J. J., \& Shufelt, J. L. (2006). Juvenile mental health courts: An emerging strategy. National Center for Mental Health and Juvenile Justice, https://www.cardozo.yu.edu/sites/default/files/Juvenile\%20Mental\%20Health\%20Courts -\%20An\%20Emerging\%20Strategy\%20\%20copy.pdf

Cocozza, J. J., \& Skowyra, K. R. (2000). Youth with mental health disorders: Issues and emerging responses. Juvenile Justice Journal, 7, 3-13. 
Colby, S. L., \& Ortman, J. M. (2015). Projections of the size and composition of the U.S. population: 2014 to 2060, United States Census Bureau,

http://www.census.gov/content/dam/Census/library/publications/2015/demo/p25-1143.pdf?

Cottle, C. C., Lee, R. J., \& Heilbrun, K. (2001). The prediction of criminal recidivism in juveniles: A meta-analysis. Criminal Justice Behavior, 28, 367-394.

Council of State Governments Justice Center. (2008). Mental health courts: A primer for policymakers and practitioners. Bureau of Justice Assistance, http://ojp.gov/newsroom/testimony/2009/mentalhealthcourts.pdf.

Deas, D. (2006). Adolescent substance abuse and psychiatric comorbidities. Journal of Clinical Psychiatry, 67, 18-23.

Development Services Group, Inc. (2010). Mental health courts. Literature review. Washington, D.C.: Office of Juvenile Justice and Delinquency Prevention, http://www.ojjdp.gov/mpg/litreviews/Mental_Health_Courts.pdf.

Development Services Group, Inc. (2011). Residential treatment centers. Literature review. Washington, D.C.: Office of Juvenile Justice and Delinquency Prevention, http://www.ojjdp.gov/mpg/litreviews/Residential_Treatment_Centers.pdf.

Drabick, D. A., Beauchaine, T. P., Gadow, K. D., Carlson, G. A., \& Bromet, E. J. (2006). Risk factors for conduct problems and depressive symptoms in a cohort of Ukrainian children. Journal of Clinical Child and Adolescent Psychology, 35, 224-252.

Espinosa, E. M., Sorenson, J. R., \& Lopez, M. A. (2013). Youth pathways to placement: The influence of gender, mental health need and trauma on confinement in the juvenile justice system. Journal of Youth and Adolescence, 12, 1824-1836. 
Fergusson, D. M., Lnskey, M. T., \& Horwood, L. J. (1996). The short-term consequences of early onset cannabis use. Journal of Abnormal Child Psychopathology, 24, 499-512.

Goodrich, D. E., Kilbourne, A. M., Nord, K. M., \& Bauer, M. S. (2013). Mental health collaborative care and its role in primary care settings. Current Psychiatry Reports, 15, 383. doi: 10.1007/s11920-013-0380-2.

Gordon, J. A., Diehl, R. L, \& Anderson, L. (2012). Does ADHD matter? Examining attention deficit and hyperactivity disorder on the likelihood of recidivism among detained youth. Journal of Offender Rehabilitation, 51, 497-518. doi: 10.1080/10509674.2012.702714

Gordon, J. A., \& Moore, P. (2005). ADHD among incarcerated youth: An investigation on the congruency with ADHD prevalence and correlates among the general population. American Journal of Criminal Justice, 30, 87-97. doi: 10.1007/BF02885883

Grant, B. F., Stinson, F. S., \& Hartford, T. C. (2001). Age at onset of alcohol use and DSM-IV alcohol abuse and dependence: A 12-year follow-up. Journal of Substance Abuse, 13, 493-504

Greenwood, P., \& Turner, S. (2009). An overview of prevention and intervention programs for juvenile offenders. Victims and Offenders, 4, 365-374. http://dx.doi.org/10.1080/15564880903227438.

Grisso, T. (2008). Adolescent offenders mental disorders. Future of Children, 18, 143-164.

Grunbaum, J. A., Kann, L., Kinchen, S., et al. (2004). Youth risk behavior surveillance—United States, 2003. Journal of School Health, 74, 307-324

Gustafson, D. T., Preston, K., \& Hudson, J. (2009). Mental health: Overlooked and disregarded in rural America. Lyon, NE: Center for Rural Affairs. Retrieved from http://www.cfra.org 
Harrison, P. A., Fulkerson, J. A., \& Beebe, T. J. (1998). DSM-IV substance use disorder criteria for adolescents: A critical examination based on a statewide school survey. American Journal of Psychiatry, 155, 486-492.

Henggeler, S. W., Halliday-Boykins, C. A., Cunninham, P. B., Randall, J., Shapiro, S. B., \& Chapman, J. E. (2006). Juvenile drug court: Enhancing outcomes by integrating evidence-based treatments. Journal of Consulting and Clinical Psychology, 74, 42-54.

Hockenberry, S., \& Puzzanchera, C. (2015). Juvenile court statistics 2013. National Center for Juvenile Justice. www.ncji.org/pdf/jcsreports/jcs2013.pdf.

Hockenberry, S., Sickmund, M., \& Sladky, A. (2015). Juvenile residential facility census, 2012: Selected findings. Juvenile Offenders and Victims: National Report Series. http://www.ojjdp.gov/pubs/247207.pdf.

Huber, B. J., Austen, J. M., Tobin, R. M., Meyers, A. B., Shelvin, K. H., \& Wells, M. (2016). Overcoming barriers to rural children's mental health: An interconnected systems public health model. Advances in School Mental Health Promotion,9, 2019-241. https://mc.manuscriptcentral.com/rasm

Illinois Department of Juvenile Justice (2016). Summary of State Fiscal Year 2015 Admissions to the Illinois Department Juvenile Justice Facilities. IDJJ Data and Reports. https://www.illinois.gov/idj]/Pages/Data-and-Reports.aspx

Johnson, T. P., Cho, Y. I., Fendrich, M., Graf, I., Kelly-, L., \& Pickup, L. (2004). Treatment need and utilization among youth entering the juvenile corrections system. Journal of Substance Abuse Treatment, 26, 117-128. doi: 10.1353/foc.0.0017 
Johnston, L. D., O’Malley, P. M., Bachman, J. G., et al. (2004). Monitoring the future. National results on adolescent drug use: Overview of key findings, 2003. Bethesda, MD. http://monitoringthefuture.org/pubs/monographs/over view2003.pdf.

Johnson, S.D., Stiffman, A., Hadley-Ives, E., \& Elze, D. (2001). An analysis of stressors and comorbid mental health problems that contribute to youths' paths to substance-specific services. Journal of Behavioral Health Services \& Research, 28, 412-426.

Justice Policy Institute. (2009). The costs of confinement: Why good juvenile justice policies make good fiscal sense. Washington, D.C. http://www.justicepolicy.org/images/upload/09_05_rep_costsofconfinement_ji_ps.pdf.

Kamradt. (1998). Wraparound Milwaukee: Aiding youth with mental health needs. Juvenile Justice Journal, 7, 14-23.

Ketcham, O. (1977). National standards for juvenile justice. Virginia Law Review, 63, 201-219.

Lenardson, J. D., Ziller, E. C., Lambert, D., Race, M. M., \& Yousefian, A. Y. (2010). Access to mental health services and family impact of rural children with mental health problems. Rural Health Research \& Policy Center, 45, 1-15.

Lewinsohn, P. M., Rhode, P., \& Seeley, J. R. (1996). Alcohol consumption in high school adolescents: Frequency of use and dimensional structure of associated problems. Addiction, 91, 375-390

Liebenberg, L., \& Ungar, M. (2014). A comparison of service use among youth involved with juvenile justice and mental health. Children and Youth Services Review, 39, 117-122.

Loeber, R., Green, S. M., Lahey, B. B., Frick, P. J., \& McBurnett, K. (2000). Findings on disruptive behavior disorders from the first decade of the Developmental Trends Study. Clinical Child and Family Review, 3, 37-60. 
Lowenkamp, C., Flores, A., Holsinger, A., Makarios, M., Latessa, E. (2010) Intensive supervision programs: Does program philosophy and the principles of effective intervention matter? Journal of Criminal Justice, 38, 368-375. http://dx.doi.org/10.1016/j.jcrimjus.2012.04.004.

Manisses Communications Group, Inc. (1999). Advocates win MH amendments to Senate juvenile crime bill. Children's Services Report, 3, 1-2.

National Center on Addiction and Substance Abuse. (2004). Criminal neglect: Substance abuse, juvenile justice and the children left behind. New York: Author. Retrieved from: file:///C:/Users/Danielle/Downloads/Criminal-neglect-substance-abuse-juvenile-justiceand-the-children-left-behind.pdf.

National Institute on Drug Abuse (1995). Prevalence of drug use in the DC Metropolitan Area adult and juvenile offender populations: 1991. Rockville, MD. http://hdl.handle.net/2027/mdp.39015038188325.

National Institute of Justice (2014). Recidivism. Retrieved from: https://www.nij.gov/topics/corrections/recidivism/Pages/welcome.aspx. Office of Applied Studies. (2000). National household survey on drug abuse: Main findings 1998. Rockville, MD: Substance Abuse and Mental Health Services Administration.

Orbis Partners Inc. (2007). Long-term validation of the youth assessment and screening instrument (YASI) in New York State juvenile probation. New York State Division of Probation and Correctional Alternatives. http://www.criminaljustice.ny.gov/opca/pdfs/YASI-Long-Term-Validation-Report.pdf 
Osgood, D. W., \& Chambers, J. M. (2003). Community correlates of rural youth violence (Juvenile Justice Bulletin). Washington, DC: U.S. Department of Justice, Office of Juvenile Justice and Delinquency.

Petersilia, J., \& Turner, S. (1993). Intensive probation and parole. Crime and Justice, 17, 281335. http://dx.doi.org/10.1086/449215.

Priester, M. A., Browne, T., Iachini, A., Clone, S., DeHart, D., \& Seay, K. D. (2016). Treatment access barriers and disparities among individuals with co-occurring mental health and substance use disorders: An integrative literature review. Journal of Substance Abuse Treatment, 61, 47-59. doi: 10.1016/j.jsat.2015.09.006.

Pollock, N. K., \& Martin, C. S. (1999). Diagnostic orphans: Adolescents with alcohol symptoms who do not qualify for DSM-IV abuse or dependence diagnosis. American Journal of Psychiatry, 91, 375-390

Puzzanchera, C., Adams, B., \& Sickmund, M. (2011). Juvenile court statistics 2006-2007. National Center for Juvenile Justice. http://www.ojjdp.gov/ojstatbb/njcda/pdf/jcs2007.pdf.

Ruiz, B. S., Stevens, S. J., McKnight, K. Godley, S. H., \& Shane, P. (2005). Treatment issues and outcomes for juvenile-justice-involved youth from rural and nonrural areas. The Prison Journal, 85, 97-121. doi: 10.117-0032885504274295

Schufelt, J. L., \& Cocozza, J. J. (2006). Youth with mental health disorders in the juvenile justice system: Results from a multi-state prevalence study. National Center for Mental Health and Juvenile Justice. http://www.unicef.org/tdad/usmentalhealthprevalence06(3).pdf. 
Sickmund, M., \& Puzzanchera, C. (2014). Juvenile offenders and victims: 2014 national report. Pittsburgh, PA: National Center for Juvenile Justice. www.ojjdp.gov/ojstatbb/nr2014/.

Sheidow, A. J., Jayawardhana, J., Bradford, W.D., Henggeler, S. W., \& Shapiro, S. B. (2012). Money matters: Cost-effectiveness of juvenile drug court with and without evidencebased treatments. Journal of Child \& Adolescent Substance Abuse, 21, 69-20. doi: 10.1080/1067828X.2012.636701.

Snyder, H. N. (2004). Juvenile arrests 2002. Juvenile Justice Bulletin. Washington, DC: U.S. Department of Justice, Office of Juvenile Justice and Delinquency Prevention. Retrieved from http://www.ncjrs.gov/html/ojjdp/204608/contents.html.

Stevens, S. J., Hasler, J., Murphy, B. S., Taylor, R., Senior, M., Barron, M., et al. (2003). La Canada adolescent treatment program: Addressing issues of drug use, gender and trauma. In S. J. Stevens \& A. R. Moral (Eds.), Adolescent substance abuse treatment in the United States: Exemplary models from a national evaluation study (pp. 183-206). Binghamton, NY: Haworth.

Teplin, L. A., Abram, K. M., McClelland, G. M., Dulcan, M. K., \& Mericle, A. A. (2002). Psychiatric disorders in youth in juvenile detention. Archives of General Psychiatry, 59, 1133-1143. doi: 10.1001/archpsyc.59.12.1133

Trupin, E. W., Turner, A. P., Stewart, D., \& Wood, P. (2004). Transition planning and recidivism among mentally ill juvenile offenders. Behavioral Sciences and the Law, 22, 599-610. 
US Department of Health \& Human Services, Substance Abuse and Mental Health Services Administrations, Office of Applied Studies. (2004). National survey on drug use and health: National findings. Rockville, MD. http://oas.samhsa.gov/nhsda/2k3nsduh/2k3results.htm.

Voices for Illinois Children (2015). Illinois Kids Count 2015: Confronting Poverty, Creating Opportunity. Chicago, IL: Author. http://www.voices4kids.org/wpcontent/uploads/2015/03/VOICES_2015KC_report_FINAL.pdf.

Vreugdenhil, C., Doreleijers, T., Vermeiren, R., Wouters, L., \& Van Den Bring, W. (2004). Psychiatric disorders in a representative sample of incarcerated boys in the Netherlands. Journal of the American Academy of Child and Adolescent Psychiatry, 43, 97-105. doi: 10.1097/00004583-200401000-00019

Weemhoff, M. M., \& Villaruel, F. A. (2011) The plight of Latino youth in the juvenile justice system: Considerations for mental health treatment. Creating infrastructures for Latino mental health (pp. 177-193). New York: Springer.

Weinrath, M., Donatelli, G., \& Murchison, M. J. (2016). Mentorship: A missing piece to manage juvenile intensive supervision programs and youth gangs? Canadian Journal of Criminology and Criminal Justice, 291-321. doi:10.31381cjccj.2015.E19.

Winstanley, E. I., Steinwachs, D. M., Stitzer, M. L., \& Fishman, M. J. (2012). Adolescent substance abuse and mental health: Problem co-occurrence and access to services. Journal of Child \& Adolescent Substance Abuse, 21, 310-322.

Zang, A. (2015). U.S. Age Boundaries of Delinquency 2014. National Center for Juvenile. Justice.http://www.ncjj.org/pdf/JJGPS\%20StateScan/JJGPS_U.S._age_boundaries_of_de linquency_2015_8.pdf. 
Table 1

Mental health concerns, treatment, and recidivism

\begin{tabular}{lcccccc}
\hline & B & SE B & $\beta$ & $t$ & $d f$ & $p$ \\
\hline Step I & & & & & & \\
Mental Health Concerns & 2.68 & 0.65 & 0.43 & 4.15 & 75 & $<.001$ \\
\hline Step II & & & & & & \\
Mental Health Concerns & 0.09 & 0.89 & 0.01 & 0.10 & 74 & .923 \\
Mental Health Treatment & 3.64 & 0.93 & 0.56 & 3.93 & 74 & $<.001$ \\
\end{tabular}

Table 2

Alcohol/substance abuse concerns, treatment, and recidivism

\begin{tabular}{lcccccc}
\hline & B & SE B & $\beta$ & $t$ & $d f$ & $p$ \\
\hline Step I & & & & & & \\
Alcohol/Substance Abuse Concerns & 2.12 & 0.67 & 0.34 & 3.14 & 75 & .002 \\
\hline Step II & & & & & & \\
Alcohol/Substance Abuse Concerns & 0.51 & 0.71 & 0.08 & 0.72 & 74 & .477 \\
Alcohol/Substance Abuse Treatment & 3.20 & 0.75 & 0.49 & 4.29 & 74 & $<.001$ \\
\hline
\end{tabular}


Table 3

Substance abuse concerns, treatment, and recidivism

\begin{tabular}{lcccccc}
\hline & B & SE B & $\beta$ & $t$ & $d f$ & $p$ \\
\hline Step I & & & & & & \\
Substance Abuse Concerns & 2.33 & 0.70 & 0.37 & 3.34 & 71 & .001 \\
\hline Step II & & & & & & \\
Substance Abuse Concerns & 0.43 & 0.79 & 0.07 & 0.54 & 70 & .593 \\
Substance Abuse Treatment & 3.31 & 0.83 & 0.50 & 4.01 & 70 & $<.001$ \\
\hline
\end{tabular}


Table 4

Total time in juvenile justice system, mental health concerns, treatment, and recidivism

\begin{tabular}{|c|c|c|c|c|c|c|c|}
\hline & B & SE B & $\beta$ & $t$ & $d f$ & $p$ & $\begin{array}{c}\text { R Square } \\
\text { Change }\end{array}$ \\
\hline Step I & & & & & & & .403 \\
\hline Total Days & 0.00 & 0.00 & 0.64 & 7.11 & 75 & $<.001$ & \\
\hline Step II & & & & & & & .007 \\
\hline Total Days in System & 0.00 & 0.00 & 0.56 & 6.45 & 74 & $<.001$ & \\
\hline MH Concerns & 1.78 & 0.54 & 0.29 & 3.30 & 74 & .001 & \\
\hline Step III & & & & & & & .038 \\
\hline Total Days in System & 0.00 & 0.00 & 0.48 & 5.37 & 73 & $<.001$ & \\
\hline MH Concerns & 0.46 & 0.76 & 0.07 & 0.61 & 73 & .546 & \\
\hline MH Treatment & 2.03 & 0.85 & 0.31 & 2.39 & 73 & .019 & \\
\hline
\end{tabular}


Table 5

Total time in juvenile justice system, alcohol/substance abuse concerns, treatment, and recidivism

\begin{tabular}{|c|c|c|c|c|c|c|c|}
\hline & B & SE B & $\beta$ & $t$ & $d f$ & $p$ & $\begin{array}{c}\text { R Square } \\
\text { Change }\end{array}$ \\
\hline Step I & & & & & & & .403 \\
\hline Total Days & 0.00 & 0.00 & 0.64 & 7.11 & 75 & $<.001$ & \\
\hline Step II & & & & & & & .107 \\
\hline Total Days in System & 0.00 & 0.00 & 0.63 & 7.71 & 74 & $<.001$ & \\
\hline A/SA Concerns & 2.03 & 0.51 & 0.33 & 4.02 & 74 & $<.001$ & \\
\hline Step III & & & & & & & .036 \\
\hline Total Days in System & 0.00 & 0.00 & 0.55 & 6.38 & 73 & $<.001$ & \\
\hline A/SA Concerns & 1.25 & 0.59 & 0.20 & 2.13 & 73 & .036 & \\
\hline A/SA Treatment & 1.58 & 0.65 & 0.24 & 2.41 & 73 & .018 & \\
\hline
\end{tabular}




\section{APPENDIX A: TRAINING MANUAL}

Welcome to the Juvenile Justice Study!

I designed this training manual to outline the duties involved in the Juvenile Justice study and provide a resource to those working with this data. The purpose of this manual is to offer detailed instructions to assure you have a smooth transition into this role. Any questions you have feel free to email me: dngiesc@ilstu.edu.

The Juvenile Justice study is part of a multi-year, large scale grant focused on improving mental health services in Livingston County. This study examines how youth involved with the juvenile justice system are serviced by the court system, focusing on how they move through the system of care, the services they receive, and their functioning throughout their care. Judge Bauknecht, the judge in Livingston County who oversees the Juvenile Court, has allowed us to examine her cases from the years 2010-2015. We have received access to those youth's probation and court files, and have been invited by the court to examine their paper records.

Shelby Bivens is Judge Bauknecht's clerk, as has been extremely helpful in our progress on this data. Shelby de-identifies electronic probation logs and provides us with those logs via a flash drive at the courthouse. Shelby helps us coordinate our trips to the court, organizing which paper files we need access to, and finding space to code at the court. She has been very helpful and responsive to e-mails. You can contact her at sbivens@ livingstoncountyil.gov. Please just remember this is not her primary responsibility and she is simply helping us out of the goodness of her heart.

Ron Baker is the head of probation at the court, and also has been extremely helpful in our progress with this data. He provides us with access to paper probation files we need, and explanations of different abbreviations that we see within the probation files. He has been very helpful and responsive to e-mails. You can contact him at rbaker@livingstoncountyil.gov. Again, please remember that this is not his primary responsibility. Ron supervises a full case load and is in charge of the probation department.

Below are specific responsibilities and instructions for each:

Connecting to the Share Drive

Getting Acquainted with the Juvenile Justice Folder

Training Researchers

Navigating the Master List

Instructions for creating Charge Codes and Classifying Charge Type

Instructions for Electronic Probation Files

How do I get Approval to go to the Court?

Important Information for Data at the Court

Instructions for Paper Court Records

Instructions for Paper Probation Records

Coding Rubrics, Data Collection Sheets, and Instructions

Navigating the Data File

Common Abbreviations List 


\section{Connecting to the Share Drive (via PC):}

In order to access the files you need for the Juvenile Justice Study, you need to have access to the Share Drive. Renée or Adena should obtain permission. They will know how to do this. Once you have permission, follow these instructions:

For Access on the lab computer:

Connect to ISUNET using your ULID and PASSWORD

Click the "File Explorer" Icon on the bottom (This icon looks like a manila file)

Select "Computer" and click on the "psy( (lcasfiles01.casit.ilstu.edu)"

Click on "ICHF"

Select the "Juvenile Justice" Folder

For Access on your personal computer:

Login to webvpn.ilstu.edu using your UILD and PASSWORD

Type in "smb://casfiles01/psy/ICHF" and click "Browse"

(If you want to be able to pull this page up easier, hit the blue "psy" at the top of the page for it to go back to a screen, check the box next to ICHF, and click "Bookmark Selected" so it is a page you can open on your home screen)

Select the "Juvenile Justice" Folder

Getting Acquainted with the Juvenile Justice Folder:

Here are the folders:

Coded Court Records

Coded Probation Logs

Completed Electronic and Paper Probation Logs

Completed Electronic Probation Logs

Completed Electronic and Court Logs

Data Collection Sheets

De-Identified Probation Logs

In Progress

Pre-Trial Services

Ready to Code

JJ Data File

JJ Master List

Juvenile Justice Abbreviations

Juvenile Justice Manual

Here is a quick overview of what information is within each file.

\section{- Coded Court Records:}

○ Within this file you will see excel spreadsheets with information only obtained at the court through the paper court files. 
- Coded Probation Logs:

○ Within this file you will see excel spreadsheets with information only obtained through the electronic probation logs. Within this folder you will also see a folder entitled Re-Coded Reliability Probation Logs.

- Re-Coded Reliability Probation Logs: This file houses the excel spreadsheets that were completed by researchers during their training.

- Completed Electronic Probation Logs:

$\circ$ Once a researcher is done extracting information from the electronic probation file, the word document is placed within this folder.

- Completed Probation and Court Logs:

$\circ$ This file houses excel spreadsheets that have information from both the electronic probation documents as well as the paper court records.

- Data Collection Sheets:

- Within this file are the sheets that are used to identify data and code information that is being put into numerical values for data analysis.

- De-Identified Probation Logs:

- Files obtained from Shelby at the court are placed into this file before any researcher has begun to extract information from the word document.

- In Progress:

$\circ$ This is where researchers put the Excel and word documents for the case that they are currently working on.

- Pre-Trial Services:

○ In this file is the excel spreadsheets that correspond to individuals who never saw the judge and only received services through the probation office and the pre-trial services program.

\section{- Ready to Code:}

- This file houses excel spreadsheets that have information from electronic probation files, paper probation files, and paper court files and are ready to be coded using the data collection sheets. Within this file you will also find a file entitled Truancy Cases.

- Truancy Cases: This file houses the excel spreadsheets for youth who were only involved in the court for truancy concerns. These files are also ready to be coded using the data collection sheets.

\section{Training Researchers}

Electronic Probation Files: Once researchers have been approved by the IRB for the study, they will receive training on the juvenile justice project. Prior to beginning coding independently, new researchers will have the purpose of the project outlined for them, where information is gathered from, and what type of information is important. Researchers will be shown the master list and taught how to read and interpret what needs to be done for different files. Researchers will then be shown the data file indicating the types of information that we will be analyzing, an example of an electronic probation file, and what a coded electronic probation file would look like. They will then receive training regarding how to determine appropriate charge codes for each individual. 
After getting a general sense of the study, researchers will spend time examining one coded electronic probation file with the corresponding excel worksheet where information has been extracted by a previous researcher. They will read through the excel worksheet to see the format for excel files, what information is extracted and where it goes in the data file. After they have read through one completed electronic probation file, they will re-code two probation files that have already been coded by another researcher. Trainees will have each excel file open and compare what types of information they extracted compared to an individual who already has been trained. Once they have completed one excel file, a trained graduate student will examine the excel files, discuss any differences that the trainee had in their file, and update the file. This process will be repeated with a second case. If trainees are coding with at least $80 \%$ reliability to the previous researcher, they can move on to the next phase of training. If not this process is repeated until $80 \%$ reliability is reached.

After two or more cases have been re-coded and checked and the trainee has shown to code with $80 \%$ reliability to previously trained researchers, the trainee will begin coding a new electronic probation file that has not been completed. When they finish this probation file, the graduate researcher will read through the coding that the trainee has completed, providing feedback as necessary. This process will be completed a second time in order to further ensure $80 \%$ reliability. Baring no further complications or concerns, the trainee has graduated and is now ready to independently code electronic probation files.

Paper Probation and Court Files: Once researchers have completed their electronic probation file training and has independently coding three electronic probation files without error, they are ready to code the paper probation and court files. Training for these files happen at the courthouse, due to limited access to these files. A new researcher will observe an experienced researcher navigate the paper files, receiving training on important paperwork to enter into existing excel files. After observing a researcher navigate and extract information from one paper file, the new researcher will begin coding a paper probation file, receiving feedback to ensure accuracy. This process will be completed a second time in order to ensure $80 \%$ reliability. Baring no further complications or concerns, the trainee has graduated and is now ready to independently code paper probation and court files.

\section{Navigating the Master List}

Reading the Master List is necessary to determine what work has been completed, and what work should be completed next. Each row represents an individual case, with the first column identifying the number attached to the case. The second column identifies what type of case (i.e., crime, parent, truancy, diverted) the files represent. The third column shows with an $\mathrm{X}$ which cases have electronic probation files that have been de-identified by Shelby at the court house and uploaded to the share drive. The following three columns identify when the type of file was completed and by who. When all three of these columns have information entered, an X is placed in the Ready to Code column. Once researchers have extracted all information from the electronic files onto paper matrices, the date of completion and initials of the researcher is placed in the Coded column. Similarly, once a secondary coder has completed the paper matrices, the 
date and initials of the researcher is placed in the Secondary Coder column. Lastly, the reliability percentage is completed by dividing the number of same answers by the number of total answers (63) to determine the rater reliability. This percentage is placed in the \% reliability column.

\section{Instructions for creating Charge Codes and Classifying Charge Type}

Charge Codes are given for every time an individual receives a charge. They follow a xxx-Xx$\operatorname{xxxx}$ format. The first three number in the sequence represent the individuals identifying number. For example, case number 3 would have a 003 as the first three numbers in the charge code. The next two numbers represent the last two digits in the year that the individual received the charge. For example, if case number 3 received a charge in the year 2014, it would look like 003-14-xxxx. The last four digits in the code represent the number of charges that the individual has received. Each of the charges start with an initial 1000 for their first charge. If the individual has multiple charges under one instance, the tens place increases by one for each charge. For example, if case number 3 received two separate charges for their first crime in 2014, the two charges would receive a code of 003-14-1000 and 003-14-1010. This same process happens if an individual has multiple counts of the same crime, with the tens place increasing by one for each count.

When an individual has a multiple charges across the same or different years, the hundreds place increases by one for each charge. For example, if case number 3 received another charge 3 months later, this charge would receive a code of 003-14-1100. Similarly, if case number 3 received another charge the following year, this charge would receive a code of 003-15-1200. As of now, the thousands and ones place does not move.

\section{Instructions for Electronic Probation Files}

First look at the JJ Master list to identify which cases are ready to be worked on. Place your initials in the selected electronic probation file to ensure no one else works on your file. Open the "De-Identified Probation Logs" file and select the corresponding file. After ensuring that no excel file has been created for the case due to paper files being completed first, create a new excel for your electronic probation file. The first column in the excel file will house the dates that the charge was given or the information was received. The second column will have charge codes. The third column will have charge descriptions, as well as the information being extracted from specific dates. The fourth column will have additional information about the charges. The fifth column will have the category of the charge, and the sixth column will have information about the status of the charge. See below for an example. 


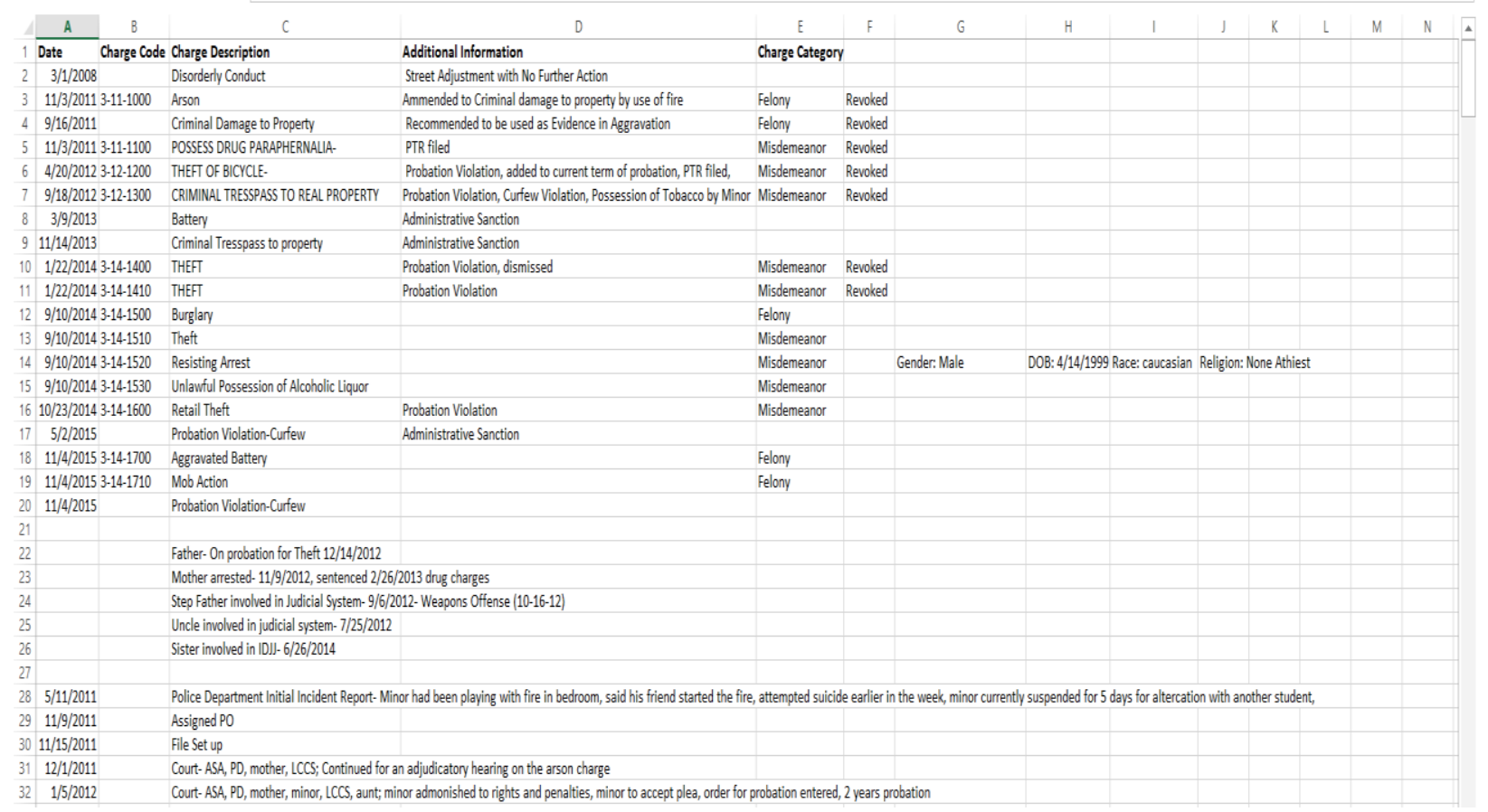

Once the excel file is set up, the researcher will read through the electronic probation file. The researcher will place the date the information that is being extracted is from in the first column, and the information being extracted in the third column. The information should be placed in the following format:

Type of contact- Who is involved; information

Information that should be extracted is any information about the individual's social, behavioral, or educational functioning.

\section{How do I get approval to go to the Court?}

Taking trips to the court is an integral part of the data collection process. Typically court trips are discussed during the weekly lab meetings, and a day and time is decided upon that best fits the most people's schedule. In order to get approval to go to the court, you need to contact BOTH Shelby and Ron. It is customary to send them the same e-mail in order to ensure that space as well as materials will be available for our trip. Judge Bauknecht oversees Juvenile Court on Thursdays, and is often willing to let researchers sit in and observe her proceedings. It is important that all researchers traveling to the court take their laptops and have access to the share drive in order to update files and upload the newest version to the appropriate files.

Duties that can only be done at the court include: 1) Obtaining new de-identified probation logs, 2) Examining both paper and court records, and 3) Updating the master list of participants.

\section{Important Information for Data at the court:}


A paper master list of participants and their corresponding information exists at the court. It is located inside the box of court files Shelby has pulled for the researchers in an expandable brown folder. Shelby uses this list to determine which files she should work on next. It is important to update this list the researchers progress each trip in order to ensure that all individuals served by the juvenile court system have been examined. An explanation of how to update the paper master list is also located at the court.

Updating the Paper Master List: Locate the participant number in the list of participant names. Once the number is located, ensure that the right hand side of the page has appropriate identifiers to show progress. A D is written if Shelby has de-identified the probation log. A P is written if researchers have examined and extracted information into excel files from that electronic probation log. A $\mathrm{C}$ is written if researchers have examined and extracted information from the paper court files. The number is highlighted if both a $\mathrm{P}$ and $\mathrm{C}$ are indicated on the right hand side of the paper. A check mark next to the highlighted number is written to indicate that the electronic probation file, paper probation file, and paper court file have all been examined and the case is ready to be coded.

\section{THIS SAME PROCESS NEEDS TO BE DONE TO UPDATE THE ELECTRONIC PROBATION FILE TO ENSURE THAT THE INFORMATION AT THE COURTHOUSE IS IDENTICAL TO THE INFORMATION WITHIN THE LAB.}

Uploading New De-identified Files: Shelby will have saved her de-identified data files onto a flash drive which is to be kept at the court. Oftentimes Shelby will have this laid out by her desk with a list of the corresponding cases that she has de-identified, however if not it is acceptable to ask her if she had any new de-identified files since the last time we were at the courthouse. In order to upload these files to the share drive, insert the USB into your computer, log into the share drive (webvpn.ilstu.edu), and go to the juvenile justice section. Open the de-identified probation $\operatorname{logs}$ file. Click the upload files button on the top right hand side of the screen. Here you can upload 5 files at a time from the USB that have been de-identified since the last time an upload was completed.

\section{Instructions for Paper Court Records}

In order to obtain paper court records, a list of individual's names needs to be created from the paper master list and given to Shelby in advance. She typically can have these files pulled the following week. These files will be placed inside a box on the back table in her office space, with our paper files that we leave at the court. Each individual will have as many files as they have charges.

It makes the most sense to update coded electronic probation files with information within the court records, as much of the information will be redundant. As most of the information is redundant, in order to further ensure all necessary information is being obtained, the researcher who has completed the electronic probation file should NOT also code the paper court file. However, information from reports and the paper documents within the court file will be new. Inside each court file there is a log of activity similar to that of the electronic probation file. Researchers will read through these dates, updating the excel spreadsheet as necessary. There is 
also information in each file regarding the charges and individual has, what classification the charges are (misdemeanor/felony), whether they have been dismissed, and what their probation entails. These files will contain many pieces of paper that include information that has not previously been extracted, so it is important to look at every piece of paper to find an associated date and ensure that information is included in the electronic files. These files may also have information regarding the individual's gender, DOB, race, ethnicity, and religion that needs to be extracted. Another piece of paper, commonly at the top of the paper list, will show a final disposition for the individual if they are no longer being seen by the judge or under probation. This information is important to include in the excel spreadsheet. Finally, a large amount of information can be obtained through reports or treatment plans that have been included in these folders. These reports should be read through with relevant information extracted and noted in the excel spreadsheet by first indicating what type of report it was followed by a - and all of the relevant information.

For example: DCFS Service Plan- minor removed from mother's care and placed with aunt and uncle, attending substance abuse and mental health counseling, etc.

Once this information has been completely added to the existing probation file, the excel file should be relocated into the file entitled Completed Probation and Court logs (If the file is one that only addresses truancy, see below). However, if additional work needs to be done on the file that cannot be completed within that sitting, it should be relocated to the file entitled In Progress. This file should be saved with the same protocol as the electronic probation files, with the new researcher adding their initials to the end (001.De-Identified.DG.MC). If the file has been moved to the completed probation file, both the paper master list and the electronic master list should be updated.

**Truancy Cases: Individuals that are only seen within the court for Truancy cases will not have any interaction with probation offices. As a result, these files should be relocated into the Truancy file within the Ready to Code file on the share drive. Additionally, the paper and electronic master lists should be updated by placing an $\mathrm{X}$ in the ready to code column and N/A in the paper and electronic probation file columns.

\section{Instructions for Paper Probation Records}

In order to obtain paper probation records, a list of individual's names needs to be created using the master list and given to Ron Baker. Ron could use at least one, but preferably two weeks notice in order to get paper probation files pulled. Paper probation files can fall into four different categories: active, partially active, not active, or deferred. Active probation records will have all of the original information that was received during the child's involvement with the court system. Partially active will have some of the information, but after a certain length of time these files are purged and not all information is kept. Not active probation files will have no probation file. Deferred probation files will have all types of information about the child's involvement with the probation office, as these individuals typically never get seen by the judge. 
Similarly to the paper court records, excel spreadsheets will be updated with information from the paper probation files. These files will be updated once information from both the electronic probation file and the paper court records have been entered. These files will have specific information about drug screens, YASI interview questions and scores, mental health and substance abuse treatment attendance, and more. All of this information should be examined, updating the excel spreadsheet where necessary.

Once this information has been completely added to the existing probation and court file, the excel file should be relocated into the file entitled Ready to Code (If the file is one that has been deferred and only received pre-trial services, see below). However, if additional work needs to be done on the file that cannot be completed within that sitting, it should be relocated to the file entitled In Progress. This file should be saved with the same protocol as the paper probation files, with the new researcher adding their initials to the end (001.De-Identified.DG.MC.DG). If the file has been moved to the ready to code file, both the paper master list and the electronic master list should be updated. Additionally, an X should be placed in the column indicating that the file is ready to be coded.

**Pre-Trial Services cases: For individuals who have been deferred and only received pre-trail services, these files should be relocated to the file entitled Pre-Trial Services. The paper and electronic master lists should be updated, with an $\mathrm{X}$ placed in the column indicating that the file is ready to be coded. Additionally, N/A should be indicated in the electronic probation file and paper court file columns.

\section{Data Collection Sheets and Instructions}

After obtaining one of each of the six data collection sheets, researcher should read through excel files in the "ready to code" file. As they are reading, tallies or phrases should be placed on corresponding data sheets in order to obtain desired information. The matrixes are in the following order: charges, court information, demographics, family contacts, MH/SA/EDU information, and professional contacts. 


\begin{tabular}{|l|l|l|l|l|l|l|l|l|l|l|}
\hline \multicolumn{7}{|c|}{ CHARGES MATRIX } \\
\hline $\begin{array}{l}\text { Char } \\
\text { ge }\end{array}$ & $\begin{array}{l}\text { Stas } \\
\text { us }\end{array}$ & $\begin{array}{l}\text { Viole } \\
\text { nt }\end{array}$ & $\begin{array}{l}\text { Se } \\
\text { x }\end{array}$ & $\begin{array}{l}\text { Proper } \\
\text { ty }\end{array}$ & $\begin{array}{l}\text { Dru } \\
\text { g }\end{array}$ & $\begin{array}{l}\text { Aggravat } \\
\text { ed }\end{array}$ & $\begin{array}{l}\text { Divert } \\
\text { ed }\end{array}$ & $\begin{array}{l}\text { Misdemea } \\
\text { nor }\end{array}$ & $\begin{array}{l}\text { Felo } \\
\text { ny }\end{array}$ & $\begin{array}{l}\text { Dismiss } \\
\text { ed }\end{array}$ \\
\hline & & & & & & & & & & \\
\hline & & & & & & & & & & \\
\hline & & & & & & & & & & \\
\hline
\end{tabular}




\begin{tabular}{|c|c|}
\hline \multicolumn{2}{|c|}{ COURT INFORMATION MATRIX } \\
\hline Initial YASI Score & \\
\hline Date of Initial YASI & \\
\hline Final YASI Score & \\
\hline Date of Final YASI & \\
\hline Number of Court Appearances & \\
\hline Final Disposition & \\
\hline Total Days of Detention Stayed & \\
\hline Total Days sentenced to Detention & \\
& \\
\hline & \\
\hline
\end{tabular}




\begin{tabular}{|c|c|}
\hline \multicolumn{2}{|c|}{ DEMOGRAPHICS MATRIX } \\
\hline Gender & \\
\hline Race & \\
\hline Hispanic & \\
\hline Birthday & \\
\hline Mother Incarcerated & \\
\hline Father Incarcerated & \\
\hline Step-Mother Incarcerated & \\
\hline Step-Father Incarcerated & \\
\hline Number of Months receiving & \\
\hline services & \\
\hline Beginning Education Level & \\
\hline Beginning Job Status & \\
\hline End Education Level & \\
\hline & \\
\hline Custody Changes & \\
\hline & \\
\hline & \\
\hline Oome Placements & \\
\hline
\end{tabular}




\begin{tabular}{|l|c|c|}
\hline \multicolumn{3}{|c|}{ FAMILY CONTACTS MATRIX } \\
\hline & $\begin{array}{c}\text { Initiated by Family } \\
\text { (Family } \rightarrow \text { Professional) }\end{array}$ & $\begin{array}{c}\text { Initiated by Professional } \\
\text { (Professional } \rightarrow \text { Family) }\end{array}$ \\
\hline PO & & \\
\hline Judge & & \\
\hline PD & & \\
\hline MH Counsel & & \\
\hline SA Counsel & & \\
\hline FSS & & \\
\hline School & & \\
\hline LCCS & & \\
\hline DCFS & & \\
\hline
\end{tabular}




\begin{tabular}{|l|l|}
\hline \multicolumn{2}{|c|}{ MENTAL HEALTH/SUBSTANCE ABUSE INFORMATION MATRIX } \\
\hline Mental Health Counseling & \\
\hline $\begin{array}{l}\text { Attended/Scheduled Mental Health Counseling } \\
\text { Appointments }\end{array}$ & \\
\hline Substance Abuse Counseling & \\
\hline $\begin{array}{l}\text { Attended/Scheduled Substance Abuse } \\
\text { Counseling Appointments }\end{array}$ & \\
\hline Sex Offender Counseling & \\
\hline $\begin{array}{l}\text { Attended/Schedule Sex Offender Counseling } \\
\text { Appointments }\end{array}$ & \\
\hline Number of Positive Drug Screen Results & \\
\hline Number of Negative Drug Screen Results & \\
\hline
\end{tabular}

\begin{tabular}{|l|l|}
\hline \multicolumn{2}{|c|}{ EDUCATIONAL INFORMATION MATRIX } \\
\hline Number of Failed Courses & \\
\hline Number of Times Retained in Grade & \\
\hline Number of Suspensions & \\
\hline Number of Expulsions & \\
\hline Number of New Educational Placements & \\
\hline Number of Unexcused Absences & \\
\hline Number of Total Absences & \\
\hline Total Number of Tardies & \\
\hline
\end{tabular}




\begin{tabular}{|c|c|c|c|c|c|c|c|c|c|c|c|}
\hline \multicolumn{12}{|c|}{ PROFESSIONAL CONTACTS MATRIX } \\
\hline & $\begin{array}{l}\text { To } \\
\mathrm{P} \\
\mathrm{O}\end{array}$ & $\begin{array}{l}\text { To } \\
\text { Judg } \\
\text { e }\end{array}$ & \begin{tabular}{|l} 
To \\
P \\
D
\end{tabular} & $\begin{array}{l}\text { To MH } \\
\text { Counse } \\
1\end{array}$ & $\begin{array}{l}\text { To SA } \\
\text { Counse } \\
1\end{array}$ & $\begin{array}{l}\text { To } \\
\text { FS } \\
\text { S }\end{array}$ & $\begin{array}{l}\text { To } \\
\text { LCC } \\
\text { S }\end{array}$ & $\begin{array}{l}\text { To } \\
\text { Schoo } \\
1 \\
\text { Admi } \\
\mathrm{n}\end{array}$ & $\begin{array}{l}\text { To } \\
\text { Teache } \\
\mathrm{r}\end{array}$ & $\begin{array}{l}\text { To } \\
\text { Truanc } \\
\text { y } \\
\text { Officer }\end{array}$ & $\begin{array}{l}\text { To } \\
\text { DCF } \\
\text { S }\end{array}$ \\
\hline $\begin{array}{l}\text { From } \\
\text { PO }\end{array}$ & & & & & & & & & & & \\
\hline $\begin{array}{l}\text { From } \\
\text { Judge }\end{array}$ & & & & & & & & & & & \\
\hline $\begin{array}{l}\text { From } \\
\text { PD }\end{array}$ & & & & & & & & & & & \\
\hline $\begin{array}{l}\text { From } \\
\text { MH } \\
\text { Counse } \\
1\end{array}$ & & & & & & & & & & & \\
\hline $\begin{array}{l}\text { From } \\
\text { SA } \\
\text { Counse } \\
1\end{array}$ & & & & & & & & & & & \\
\hline $\begin{array}{l}\text { From } \\
\text { FSS }\end{array}$ & & & & & & & & & & & \\
\hline $\begin{array}{l}\text { From } \\
\text { LCCS }\end{array}$ & & & & & & & & & & & \\
\hline $\begin{array}{l}\text { From } \\
\text { School } \\
\text { Admin }\end{array}$ & & & & & & & & & & & \\
\hline $\begin{array}{l}\text { From } \\
\text { Teache } \\
\mathrm{r}\end{array}$ & & & & & & & & & & & \\
\hline $\begin{array}{l}\text { From } \\
\text { Truanc } \\
\mathrm{y} \\
\text { Officen }\end{array}$ & & & & & & & & & & & \\
\hline $\begin{array}{l}\text { From } \\
\text { DCFS }\end{array}$ & & & & & & & & & & & \\
\hline
\end{tabular}




\section{Navigating the Data File}

The data file has columns corresponding to the information extracted in the data collection sheets. Each individual has a separate row. Information from the data collection sheets should be placed in the corresponding space in the row for the participant.

\section{Common Abbreviations List}

JD = Juvenile Delinquent (JUVE)

$\mathbf{C C}=$ Criminal Contempt

$\mathbf{O V}=$ Ordinance Violation

$\mathbf{C}=$ Civil

$\mathbf{T R}=$ Traffic

DT $=$ DUI Traffic

$\mathbf{C M}=$ Criminal Misdemeanor

$\mathbf{C F}=$ Criminal Felony

$\mathbf{S C}=$ Small Claims (CIVIL)

$\mathbf{T}=$ Truancy? (JUVE)

JA = Neglect or Abuse (JUVE)

$\mathbf{F}=$ Family (CIVIL)

$\mathbf{D}=$ Deviance (CIVIL)

DET $=$ Detention or Bond Hearing

ARRN = Arraignment

STATUS = Status (Review in court?)

ADJ TRIAL = Adjudication or Trial

DISP or SENT $=$ Disposition or Sentencing

REV $=$ Review

PTR $=$ Petition to Revoke

MOT $=$ Motion to Life Stay

PTM $=$ Petition to Modify

PET $=$ Petition

$\mathbf{O V}=$ Office Visit

$\mathbf{H V}=$ Home Visit

PC or TX = Phone Call

PCNA = Phone Call No Answer

$\mathbf{E V}=$ Employment Visit

SV $=$ School Visit

HVNT = Home Visit Not There

YASI or CASEWORKS $=$ Youth Assessment Screening Inventory

$-\mathrm{L}=$ Low Risk

-M = Moderate Risk

$-\mathrm{H}=$ High Risk

FTR $=$ Failure to Report

INIT ASSESS = Initial Assessment

REASS $=$ Reassess

CTS or $\mathbf{C T}=\operatorname{Court}(\mathrm{s})$ 
FTF $=$ Face to Face or Status update before court appearance

DOC $=$ Department of Corrections

$\mathbf{R} / \mathbf{O}=$ Resource Officer (At School)

$\mathbf{T} / \mathbf{O}=$ This Officer

SAO = States Attorney's Office

$\mathbf{S A}=$ States Attorney

HC $=$ Home Confinement

CDP or CD to $\mathbf{P}=$ Criminal Destruction of Property

ARRN= Arraignment ( $1^{\text {st }}$ intro to court process)

$\mathbf{A S}=$ Action Step

NTR $=$ Notice to Report (?)

UDIS = Unified Delinquency Intervention Services Program

$\mathbf{E M}=$ Electronic Monitoring

MHJJ = Mental Health Juvenile Justice

SH $=$ Social History

BI = BI Inc. (possibly electronic monitoring?)

PD $=$ Public Defender

LCSP = Livingston County

LMOM = Left Message on Machine

Street Adjustment $=$ This is a dispositional

option for a new police contact- basically no action taken by SA after they got the report. Officer's handling the situation was deemed to be enough, or there was not enough evidence to prove an offence occurred.

PAICC $=$ Petition for Adjudication of Indirect Criminal Contempt (type of charge that can be filed alleging Contempt

AIOC form = Administrative Office of the Illinois Courts form (a document that has to be completed for statistical purposes when a juvenile is detained)

F/C/A = Fines/Costs/Assessments

PCS = Public/Community Service

"Scored as a 13" or "Scored Minor Out" = Scoring instrument used to decide if a minor will be detained after a new arrest or released to parents.

"Score out" is a bad thing. Any time a police officer wants a minor detained for a new arrest they contact us, and there is a scoring instrument we use to determine if they will be detained or not. Comes from AOIC. Scores them based upon history, the current offense, risk, etc. We are not bound by the score - a supervisor can override up or down, but $95 \%$ of the time the scoring instrument drives whether or not they go to detention versus being released to parents pending the charges.

JPTS = Juvenile Pre Trial Supervision

K\&V Admission = Knowing and voluntary admission

FB Presented $=$ Factual basis

CIPP = Clinical Intervention to Placement Preservation 
$\mathbf{R O P}=$ stands for "Report of Probation". This is the report we generate and send to the State's Attorney when we want them to consider filing a Petition to Revoke or take other action against a client for violating. Basically at that point we have done all of the administrative sanctions or other actions that we think would have an influence on our own and are asking that they be taken back before the Judge to face a consequence.

$\mathbf{R}$ of $\mathbf{P}$ is Report of Probation, again.

MCDC $=$ is the McLean County Detention Center. Any time a minor is detained, either by our decision or by and order from the Judge, we contact the Sheriff's Department to transport the minor from here to the detention center.

The minor would have been transported - that would have been a presumption on our part based upon the fact that the detention center did not call us looking for him after he did not arrive :)

$\mathbf{E M H}=$ is a special education designation. Believe it stands for Educable Mentally Handicapped. CUS $=$ is a Continuance Under Supervision. The notes probably should have reflected that the officer "went over" (reviewed) the order with minor and parents. It is a type of probation except if the minor successfully completes it the case is dismissed at the end of the term. Usually we handle it the same as regular probation - except sometimes you'll see the Judge order "unsupervised" CUS. We are not involved with that and that is more like typical court supervision - an honor system. They have to do things/get things completed but no one is actively checking on them.

PV- Probation Visit 
APPENDIX B: TREATMENT COMPLIANCE MATRIX

\begin{tabular}{|c|c|c|}
\hline Participant ID Number & $\begin{array}{c}\text { Positive Treatment } \\
\text { Compliance Statement }\end{array}$ & $\begin{array}{c}\text { Negative Treatment } \\
\text { Compliance Statement }\end{array}$ \\
\hline Mental Health Counseling & & \\
\hline $\begin{array}{c}\text { Alcohol/Substance Abuse } \\
\text { Treatment }\end{array}$ & & \\
\hline
\end{tabular}

